The Role of Interpersonal Influence in Counterbalancing Psychopathic Personality Trait Facets at Work

Schütte, Nora; Blickle, Gerhard; Frieder, Rachel E.; Wihler, Andreas; Schnitzler, Florian; Heupel, Janis; Zettler, Ingo

Published in:

Journal of Management

DOI:

$10.1177 / 0149206315607967$

Publication date:

2018

Document version

Peer reviewed version

Citation for published version (APA):

Schütte, N., Blickle, G., Frieder, R. E., Wihler, A., Schnitzler, F., Heupel, J., \& Zettler, I. (2018). The Role of Interpersonal Influence in Counterbalancing Psychopathic Personality Trait Facets at Work. Journal of Management, 44(4), 1338-1368. https://doi.org/10.1177/0149206315607967 
This work is scheduled to appear in

Journal of Management

(C) 2015 Southern Management Association / SAGE Journals

This manuscript may not exactly replicate the final version published in the journal. It is not the copy of record.

Reference:

Schütte, N., Blickle, G., Frieder, R. E., Wihler, A., Schnitzler, F., Heupel, J., \& Zettler, I. (accepted for publication). The role of interpersonal influence in counterbalancing psychopathic personality trait facets at work. Journal of Management. 


\title{
THE ROLE OF INTERPERSONAL INFLUENCE IN COUNTERBALANCING PSYCHOPATHIC PERSONALITY TRAIT FACETS AT WORK
}

\author{
NORA SCHÜTTE AND GERHARD BLICKLE \\ Universitaet Bonn
}

RACHEL E. FRIEDER

Old Dominion University

ANDREAS WIHLER, FLORIAN SCHNITZLER AND JANIS HEUPEL

Universitaet Bonn

INGO ZETTLER

University of Copenhagen

Accepted for publication by

\section{Journal of Management}

$(08-27-15)$

Supplemental material for this article is available at http://xxx.sagepub.com/supplemental

Acknowledgements: The authors would like to express their gratitude to Rainer Banse and

Gerald R. Ferris for their thorough and insightful comments on a previous draft of this paper.

Corresponding author: Gerhard Blickle, Arbeits-, Organisations- und Wirtschaftspsychologie Institut fuer Psychologie, Universitaet Bonn

Kaiser-Karl-Ring 9, 53111 Bonn, Germany

Fon: +49 228734375 , Fax: +49228 734670

E-mail: gerhard.blickle@uni-bonn.de 


\begin{abstract}
The purpose of this study was to examine the relations of two facets of psychopathic personality (i.e., self-centered impulsivity, fearless dominance) with counterproductive work behavior (CWB-I) and contextual performance (CP). Consistent with research on psychopathy, we suggested that self-centered impulsivity (i.e., behavioral impulsivity characterized by disregard for rules and responsibilities) would be positively related to CWBI and negatively related to $\mathrm{CP}$. Underpinned by socioanalytic theory, we further suggested that fearless dominance (i.e., an egotistical personal style characterized by self-promotion and prioritization of one's own needs before those of others) would only be negatively associated with interpersonal performance (i.e., high CWB-I and low CP) when individuals indicated low levels of interpersonal influence (i.e., a dimension of political skill reflecting an ability to adapt one's behavior in subtle, sophisticated, and situationally effective ways). Results provided strong support for the differential relations of the psychopathic personality dimensions with the criteria of interest. Implications for theory, practice, and future research are provided in light of a number of notable strengths and limitations.
\end{abstract}

Keywords: psychopathy; interpersonal influence; counterproductive work behavior, contextual performance 


\section{THE ROLE OF INTERPERSONAL INFLUENCE IN COUNTERBALANCING PSYCHOPATHIC PERSONALITY TRAIT FACETS AT WORK}

Individuals with elevated levels of psychopathy are characterized by callousness, remorselessness, dishonesty, lack of forethought, impulsivity, and inability and/or failure to establish close interpersonal relationships (Cleckley, 1988; Hare, 1999). The personalitybased approach to psychopathy (Lilienfeld \& Fowler, 2006) suggests that individuals with forensic (i.e., clinical/criminal) levels of psychopathy have the same personality profiles as their sub-clinical (i.e., non-criminal) counterparts; this personality-based characterization maintains that individuals with clinical versus subclinical levels of psychopathy are only distinguished from one another based on the frequency, degree, and magnitude with which they engage in the aforementioned aberrant behaviors (LeBreton, Binning, \& Adorno, 2006). In other words, psychopathy is a personality characteristic that exists on a continuum such that individuals can demonstrate low, moderate, or high levels of psychopathy (Lilienfeld \& Fowler, 2006). This characterization is consistent with recent developments in the clinical field of personality disorders. Specifically, personality disorders have even been conceptualized as extreme, maladaptive variants of "normal" personality characteristics (e.g. Costa \& Widiger, 1994; Dyce, 1997; Widiger \& Trull, 2007), a notion that has been integrated in the most recent edition of the Diagnostic and Statistical Manual of Mental Disorders (DSM-5, American Psychiatric Association, 2013).

Recent meta-analytic research has found that psychopathy is both conceptually distinct from the other dark triad traits (i.e., Machiavellianism, narcissism), and a significant predictor of job performance and various counterproductive work behaviors (e.g., O’Boyle, Forsyth, Banks, \& McDaniel, 2012; Wu \& LeBreton, 2011). Nonetheless, despite the grossly negative characterization of individuals high in psychopathy, the relation of psychopathy to performance, although negative, was quite small ( $r_{c}=-.10$; O'Boyle et al., 2012) while the relation of psychopathy to counterproductive work behavior was again quite small, although 
(expectedly) positive ( $r_{c}=.07$; O'Boyle et al., 2012). These lackluster findings suggest that an examination of the facets of psychopathic personality and/or interactions with other constructs may warrant closer consideration.

Psychopathy is a multidimensional personality construct whose hallmarks are affective deficiency (e.g., guiltlessness, low anxiety), a deceptive and egotistical interpersonal style (e.g., egocentrism, belief that rules don't apply to them), and behavioral impulsivity (e.g., thrill-seeking, irresponsibility). These factors are thought to comprise either two (e.g., Factor 1 [comprising the interpersonal and affective features] and Factor 2 [comprising impulsivity, disinhibition, and antisocial features], Hare, 2003) or three distinct factors (e.g., coldheartedness, fearless dominance, and self-centered impulsivity, Benning, Patrick, Blonigen, Hicks, \& Iacono, 2005; Lilienfeld \& Widows, 2005). Regardless of the factor structure, psychopathic personality seems to be comprised of affective, behavioral, and stylistic tendencies; thus, there is reason to suspect that the dimensions of psychopathy may be differentially related to criteria of interest and could account for the weak meta-analytic findings found by O’Boyle and colleagues (2012).

To this end, we examine the relations of the self-centered impulsivity and fearless dominance facets of psychopathic personality with two important organizational outcomes, namely interpersonally-directed counterproductive work behavior (CWB-I) and contextual performance $(\mathrm{CP})$. We do not develop hypotheses regarding the relation of the coldheartedness dimension of psychopathy with either counterproductive (CWB-I) or productive (CP) behaviors, as cold-heartedness represents an affective, as opposed to a behavioral, deficiency (Cooke \& Michie, 2001) or tendency. Alternatively, consistent with clinical and subclinical research on psychopathy, we suggest that individuals with psychopathic personalities are driven by a strong desire to get ahead, and should do so with disregard for getting along; thus individuals who score highly on self-centered impulsivity should be more likely to engage in CWB-I and should be less likely to engage in CP. 
Individuals scoring high in fearless dominance are thought to have a self-promotive, deceptive and egotistical interpersonal style (Cooke \& Michie, 2001); while individuals high in fearless dominance seek the attention of others, place their needs ahead of others, and seek special treatment, this does not necessarily imply that they will do so by engaging in CWB-I or abstaining from CP. Instead, whether this interpersonal style results in undesirable interpersonal behavior is hypothesized to depend on individual differences in social skill. More specifically, utilizing socioanalytic theory (Hogan \& Shelton, 1998), we suggest that individuals with elevated levels of fearless dominance and interpersonal influence, a dimension of political skill, should be better suited to package and present their interpersonal style in a manner that allows them to get ahead without being perceived as acrimonious and entirely agentic. As such, individuals high in fearless dominance and interpersonal influence should be perceived as engaging in less CWB-I and more $\mathrm{CP}$ as compared to their counterparts who are high in fearless dominance but low in interpersonal influence.

The present examination of psychopathic personality and interpersonal influence in the workplace boasts numerous contributions to both literatures. First, this paper contributes to the scant body of research examining psychopathic personality in organizational settings. More importantly, perhaps, this paper examines the different dimensions of psychopathy and how they may differentially relate to important workplace behaviors. As such, this manuscript examines one possible explanation for the lackluster effect sizes identified by previous metaanalytic research (i.e., O'Boyle et al., 2012). We feel it is important to distinguish between, and make differential predictions regarding the psychopathic personality dimensions. This is especially important given that the psychopathic personality trait is characterized by a widerange of affective, cognitive, and behavioral dysfunctions and/or impairments, any number of which individuals may experience, and each undoubtedly exerting differential effects on the various aspects of one's organizational experiences (e.g., work attitudes, behaviors, and interpersonal interactions). 
Additionally, this study contributes to the growing body of research suggesting that political skill is a social competency that stands to benefit the individual in its possession as well as organizational bystanders (Ferris et al., 2007). Despite the fact that the four political skill dimensions (i.e., apparent sincerity, networking ability, social astuteness, and interpersonal influence; Ferris et al., 2005) have always been conceptualized as distinct, albeit related, concepts comprising a comprehensive set of affective, behavioral, and cognitive social competencies (Ferris et al., 2007), the effects of political skill are most often examined in the aggregate (see Wihler, Blickle, Ellen III, Hochwarter, \& Ferris, 2014 for a notable exception). Nonetheless, recent calls have drawn attention to the desperate need to investigate the relations of the individual political skill dimensions to various organizational phenomena of interest (Ferris, Treadway, Brouer, \& Munyon, 2012). Therefore, this manuscript contributes to the political skill literature in that we take a more nuanced view of the construct by examining how interpersonal influence may impact the relations of fearless dominance, counterproductive work behavior, and contextual performance. Finally, this research contributes to socioanalytic theory (Hogan \& Shelton, 1998) as we examine one of the more extreme and acrimonious personality traits driven by the motive to get ahead (Kaiser, LeBreton, \& Hogan, 2015).

\section{THEORETICAL FOUNDATIONS AND HYPOTHESIS DEVELOPMENT ${ }^{1}$}

\section{Psychopathy}

Although originally studied within clinical settings among individuals incarcerated for some of the most heinous crimes in history, psychopathy represents a collection of malevolent, exploitive, agentic, and callous personality traits (Babiak \& Hare, 2006; Cleckley, 1988; Hare, 1999). People with extremely elevated levels of psychopathic personality are commonly referred to as "clinical psychopaths" (LeBreton et al., 2006); however, such individuals comprise only roughly $1 \%$ of the population (Hare, 1999). Nonetheless, because psychopathic personality exists on a continuum, research estimates that roughly $10 \%$ of 
individuals possess more moderate levels of these tendencies (LeBreton et al., 2006); as such individuals with these subclinical levels of psychopathy are still able to function both at work and within society at large.

High levels of psychopathy are characterized by selfish conduct, manipulativeness, remorselessness, arrogance, low levels of fear and anxiety, ego-centrism, impulsiveness, and pursuit of unmitigated agency (Boddy, 2006; Paulhus \& Williams, 2002). Given that individuals with elevated levels of psychopathy are highly self-confident, they often engage in grandiose and arrogant displays of self-promotion (LeBreton et al., 2006; Lynam \& Widiger, 2007). Individuals with high levels of psychopathic personality trait tend to be charming, outgoing, cool under pressure, and willing to take risks (Hare, 1999; LeBreton et al., 2006), which are characteristics they deploy to successfully influence others. Moreover, a hallmark of individuals with elevated levels of psychopathy is their lack of empathy, guilt, and remorse (Decuyper, Pauw, Fruyt, de Bolle, \& de Clercq, 2009). Those with high levels of psychopathic personality traits are unable to forge meaningful personal relationships with others, largely due to their disregard for norms of social exchange (O'Boyle et al., 2012), their serial deceit, and maliciousness towards others (Babiak \& Hare, 2006). Thus, as a testament to their paucity of the more communal traits (Paulhus \& Williams, 2002), individuals with elevated levels of psychopathy are able to use and abuse others as stepping-stones to achieve their own self-interests and personal needs without any regard for the harm, pain, or discomfort they cause to such victims.

Research suggests that these tendencies can be subsumed by two orthogonal overarching factors, fearless dominance and self-centered impulsivity; cold-heartedness does not load on either factor; Lilienfeld \& Widows, 2005; Patrick, Edens, Poythress, \& Lilienfeld, 2006). Cold-heartedness ( $\mathrm{CH})$ captures the deficient affective experience of individuals with elevated levels of psychopathy (e.g., guiltlessness, low anxiety); accordingly, individuals with elevated levels of cold-heartedness experience little guilt, show little concern, empathy, or 
sense of loyalty to others, and maintain low levels of both anxiety and fear (Cleckley, 1988; Hare, 1999). Fearless dominance (FD) captures the deceptive and egotistical interpersonal style (e.g., egocentrism, belief that rules don't apply to them) of individuals with elevated levels of psychopathy. Individuals with elevated levels of fearless dominance seek and get attention by others, are resilient to stress, and experience no social fear; moreover, such individuals tend to engage in self-promotion behaviors, tend not to abide by common rules of exchange, and, perhaps not surprisingly, put their needs before others (Boddy, 2006; Hare, 1999; LeBreton et al., 2006; O’Boyle et al., 2012).

Finally, the self-centered impulsivity (SCI) component of psychopathic personality indicates that such individuals are thrill-seeking, lacking diligence, and unconcerned with deadlines or responsibilities; as a function of this impulsivity and irresponsibility, individuals with elevated SCI often pursue means to satiate their immediate needs. Moreover, such individuals oftentimes blame others for what befalls them, fail to think their actions through, and struggle to forge meaningful, lasting relationships with others (e.g., coworkers; Cleckley, 1988; Hare, 1999). Previous meta-analytic research (O’Boyle et al., 2012) has found substantial, but very low associations between overall psychopathy scores, counterproductive work behaviors, and job performance suggesting the likelihood that subtle differences exist among the different dimensions of psychopathy and/or the existence of moderating effects.

Accordingly, we suggest that certain dimensions of psychopathy will be differently related to undesirable interpersonal performance domains, namely interpersonally-directed counterproductive work behavior and contextual performance. Given that cold-heartedness reflects a deficient affective experience (Cooke \& Michie, 2001), we do not expect to observe an association of this facet of psychopathy and the interpersonal performance domains of interest (i.e., interpersonal counterproductive work behavior, contextual performance.

However, we do suggest that self-centered impulsivity will be positively related to counterproductive work behaviors directed toward individuals (CWB-I), which are those 
discretionary employee behaviors that violate interpersonal norms at work and threaten employees' well-being (Bennett \& Robinson, 2000). Not surprisingly, individuals with elevated levels of aggregate psychopathy have demonstrated a strong proclivity for destructive (Baysinger, Scherer, \& LeBreton, 2014), hostile, and deceptive behavior (Cleckley, 1988; Hare, 1999). What's more, individuals with high SCI demonstrate an unrelenting pursuit of personal desires combined with a blatant disregard for organizational norms, distaste for responsibilities, rules, and deadlines, and lack of loyalty to their employer or coworkers (O’Boyle et al., 2012). Moreover, their inability to form meaningful interpersonal connections and their maliciousness towards others should increase the likelihood that individuals with elevated levels of self-centered impulsivity will engage in CWB-I. More formally:

Hypothesis 1: Self-centered impulsivity will be positively associated with (other-rated) interpersonally directed counterproductive work behavior.

We also hypothesize that self-centered impulsivity will be negatively related to contextual performance. Considered a form of performance distinct from task performance (Motowidlo \& van Scotter, 1994), contextual performance (CP) refers to those volitional interpersonal behaviors that go beyond task accomplishment to support the context in which work occurs (van Scotter \& Motowidlo, 1996). Such behaviors include self-disciplined behaviors such as working hard, taking initiative, following organizational rules (job dedication) and being considerate, cooperative, and assisting coworkers with their tasks (interpersonal facilitation; van Scotter \& Motowidlo, 1996). Individual who have high levels of job dedication are motivated to deliberately act in the best interest of the organization (van Scotter \& Motowidlo, 1996).

Individuals with elevated levels of self-centered impulsivity are hypothesized to engage in less contextual performance. Specifically, such individuals seek immediate gratification of their wants and needs; contributing to the social context in which task 
performance takes place is unlikely to aid them with their needs in the short-term. Moreover, individuals with high levels of SCI are impulsive thrill-seekers who struggle to maintain work-related relationships (Harpur, Hart, \& Hare, 1994); moreover, high SCI is associated with impulsivity, disdain for responsibilities, and blame externalization (Lilienfeld \& Widows, 2005). Thus, individuals with elevated levels of self-centered impulsivity should not be concerned with assisting or cooperating with others (interpersonal facilitation) nor should they be motivated to deliberately support the organization's objectives (job dedication). Therefore, we hypothesize the following:

Hypothesis 2: Self-centered impulsivity will be negatively associated with (otherrated) contextual performance.

While we hypothesize that self-centered impulsivity will be positively associated with counterproductive behavior directed towards individuals and negatively associated with contextual performance, we also suggest that fearless dominance will be negatively associated with interpersonal performance only if employees indicate low levels of interpersonal influence. In other words, we suggest that fearless dominance and self-centered impulsivity are not uniformly related to interpersonal performance in the workplace. Socioanalytic theory provides support for this notion.

\section{Socioanalytic Theory}

Socioanalytic theory suggests that there exist two basic motives underlying individuals' personalities: the desire to get ahead and the desire to get along. Individuals who are motivated to get ahead desire power, status, and control over resources (Hogan \& Shelton, 1998). As such, they achieve this motive by seeking recognition, maximizing their visibility, engaging in competition, and pursuing additional responsibilities (Hogan \& Holland, 2003). Contrarily, individuals who are motivated to get along wish to feel supported, liked, and accepted (Hogan \& Shelton, 1998). As such, they achieve this motive by being friendly, cooperative, and compliant (Hogan \& Shelton, 1998). Not surprisingly, these motives 
sometimes can represent opposing forces although they are orthogonal in many populations (Digman, 1997), such that one's ability to be seen as friendly, cooperative, and compliant runs counter to one's ability to seek power, status, and recognition (Hogan \& Shelton, 1998).

Nonetheless, according to socioanalytic theory, differences exist both in the strength or extent to which individuals possess these motives as well as individuals' strategies and/or capabilities to pursue these motives (Hogan \& Shelton, 1998). In essence, one's motives to get ahead and/or get along reflect individuals' interpersonal aspirations (i.e., what one aspires to do; Hogan \& Shelton, 1998). However, not everyone who aspires to get along and/or get ahead is equally equipped to do so. Accordingly, whether individuals are successful at pursuing either or both of these basic motives will depend on their social competence (i.e., social skill).

Social skill refers to individual differences regarding how one goes about pursuing their motives. As such, individuals who are socially skilled are more capable of translating their basic motives (i.e., their aspirations) into purposeful and, more importantly, successful action (Hogan \& Shelton, 1998). Given the widespread evidence establishing its role as an important workplace-specific social competency (e.g., Munyon, Summers, Thompson, \& Ferris, 2015), we examine whether interpersonal influence, a dimension of political skill, is capable of transmitting high levels of fearless dominance into more well-received peer evaluations of interpersonal performance behaviors.

The interpersonal influence dimension of political skill. Political skill is a comprehensive amalgamation of social competencies reflecting "the ability to effectively understand others at work, and to use such knowledge to influence others to act in ways that enhance one's personal and/or organizational objectives" (Ferris et al., 2005, p. 127). This set of social competencies is comprised of four dimensions: social astuteness, interpersonal influence, apparent sincerity, and networking ability. Social astuteness refers to the uncanny ability to observe, understand, and accurately interpret one's own behavior, the behavior of 
others, as well as social interactions, whereas interpersonal influence reflects individuals' ability to utilize such observations and keen understanding to adapt one's behavior in situationally appropriate and influential ways (Ferris et al., 2005). The apparent sincerity dimension of political skill suggests that such individuals are able to disguise ulterior motives and present themselves in a sincere and trustworthy manner. Finally, politically skilled individuals are adept networkers in that they are well-suited to establish and position themselves among powerful coalitions of influential others. Not surprisingly, both singlestudy and meta-analytic research have established political skill as a powerful and consistent predictor of various types of work performance and other important workplace outcomes (Munyon et al., 2015).

Nonetheless, the political skill dimensions have always been conceptualized as related, yet distinct concepts that should operate in theoretically distinct ways. In support, research has found that each of the four dimensions of political skill have unique personal ability antecedents (Ferris et al, 2007; Ferris et al., 2008). Unfortunately, the majority of research on political skill has been conducted at the aggregate construct level despite calls for research examining how the dimensions differentially predict workplace phenomena (Ferris et al., 2007; Ferris et al., 2012). In response to such calls, Wihler and colleagues (2014) found that social astuteness moderated the relation between climate for personal initiative and personal initiative while interpersonal influence moderated the relation between self-assessed personal initiative and supervisors' ratings of job performance. They suggested that social astuteness assisted individuals with opportunity recognition, whereas interpersonal influence equipped individuals with the ability to capitalize on opportunities. Evidence across three independent studies provided support for their hypotheses, concluding that individuals indicating high levels of interpersonal influence were able to properly calibrate and present social action so as to be favorably perceived and interpreted by others (Wihler et al., 2014).

Accordingly, we focus on the role of interpersonal influence dimension, because it is 
the dimension of political skill that best captures individuals' ability to tailor their initiatives (e.g., to get ahead) in such a way as to yield favorable evaluations from others (Wihler et al., 2014). Contrarily, the affective component of political skill, apparent sincerity, captures the ability to appear genuine and trustworthy, whereas the networking ability and social astuteness components of political skill primarily capture opportunity recognition and resource acquisition skills (Wihler et al., 2014). Accordingly, while certain individuals may be capable of appearing sincere and/or may be capable of recognizing (social astuteness) and acquiring resources (networking ability), we hypothesize that it is those individuals who are interpersonally influential who will be able to capitalize on their social skills by performing in interpersonally effective ways. More specifically, by definition, individuals with high levels of interpersonal influence should be able to behave in ways that evoke positive reactions from others (Ferris et al., 2005, 2007). Thus, interpersonally influential individuals should be perceived as engaging in fewer behaviors that harm organizational members (CWB-I) and more behaviors that contribute positively to the social context in which work takes places (contextual performance). More formally:

Hypothesis 3: Interpersonal influence will be negatively associated with (other-rated) interpersonally directed counterproductive work behavior.

Hypothesis 4: Interpersonal influence will be positively associated with (other-rated) contextual performance.

Finally, if interpersonal influence represents a form of social skill that allows individuals in its possession to behave in situationally appropriate, rapport and likinginducing, and ultimately, interpersonally effective ways, then it follows that such a skill would be useful in translating the desires to get ahead of those individuals scoring highly on the fearless dominance dimension of psychopathy into effective action.

\section{Interaction of Fearless Dominance $x$ Interpersonal Influence on Interpersonal}

\section{Performance Domains}


Recent research employing socioanalytic theory has found that, in the aggregate, political skill is a useful social competency that helps individuals to package and present their motives to get along and get ahead into organizational successes. For instance, Blickle and colleagues (Blickle, Wendel, \& Ferris, 2010) found that car salespeople who were both motivated to get ahead (as operationalized by extraversion) and politically skilled reported heightened levels of car sales on average than their less-politically skilled peers. Similarly, research has found individuals' motives to get ahead and to get along (Blickle, Fröhlich, et al., 2011) were more strongly related to positive performance ratings when individuals demonstrated heightened levels of political skill. We suggest, however, that one particular aspect of political skill (i.e., interpersonal influence) should be related to the social aspect of psychopathy (i.e., fearless dominance) but not to the intra-psychic aspects (self-centered impulsivity, cold-heartedness) of psychopathy.

Therefore, we hypothesize that individuals with elevated levels of fearless dominance who are in possession of interpersonal influence should be more capable of translating their unrelenting desire to get ahead in such a manner as to be perceived by coworkers to be less engaged in maladaptive performance (i.e., interpersonal directed counterproductive work behavior) and more engaged in performance that supports the social fabric of the organization (i.e., contextual performance). The goals of individuals characterized by fearless dominance are getting the attention of others, being the center of social interactions, and achieving one's will (manipulation; Lilienfeld \& Widows, 2005). This oftentimes manifests itself in an arrogant interpersonal style, egocentrism, and prioritization of one's own needs and wants before those of others. Those with high levels of fearless dominance do not respect the unwritten interpersonal rules and tend not to abide by common rules of exchange (Cleckley, 1988; Hare, 1999; Lilienfeld \& Widows, 2005).

Thus, without the social skill to keep these tendencies and off-putting interpersonal style in check, individuals with high levels of fearless dominance should be perceived by 
others to engage in harmful behaviors in pursuit of their need satiation and quest for special treatment (i.e., CWB-I) and not engage in those behaviors that support the social fabric of the organization (i.e., CP). Contrarily, individuals who are interpersonally influential have a subtle, yet effective communication style that enables them to conduct themselves in rapportinducing ways (Ferris et al., 2005). Moreover, they are able to adapt and calibrate their behavior in situationally appropriate ways that engender important others' (e.g., supervisors, peers) favorable evaluations (Wihler et al., 2014). Therefore interpersonally influential individuals should be able to appropriately package and/or disguise their attention-seeking and self-serving motives (i.e., motives get ahead) in ways that do not appear to harm others and that do appear to support the social context as well as the organization's (as opposed to self) interests.

Taken together, while the self-centered impulsivity dimension of psychopathic personality should always be related to negative interpersonal behavior (i.e., CWB-I) or the abstention from positive interpersonal performance (i.e., CP), fearless dominance should be differentially related to interpersonal performance domains depending on whether such individuals are in possession of interpersonal influence. Based on the tenets of socioanalytic theory, we argue that interpersonal influence should help those individuals high in fearless dominance present their motives to get ahead in a manner that is, or appears to be, less selfserving and insensitive to others. More simply, high levels of interpersonal influence and fearless dominance should be associated with lower instances of other-rated interpersonal directed counterproductive work behaviors and heightened reports of other-rated contextual performance. Therefore, the following hypotheses are offered:

Hypothesis 5: Interpersonal influence moderates the fearless dominance-counterproductive work behavior, directed toward individuals, relation. Specifically, if interpersonal influence is low (high), there is a positive (null) relation between fearless dominance and (other-rated) counterproductive work behavior directed toward 
individuals.

Hypothesis 6: Interpersonal influence moderates the fearless dominance-contextual performance relation. Specifically, if interpersonal influence is low (high), there is a negative (null) relation between fearless dominance and (other-rated) contextual performance.

\section{METHOD}

\section{Participants and Procedures}

The study took place in the western part of Germany; 523 employees from a broad range of jobs were personally contacted by 27 psychology students in partial fulfilment of their study requirements. Potential participants were asked if they would like to take part in an online study of personality and social competencies in the workplace and if they would ask at least two co-workers to provide a job-related assessment of their behavior at work. Coworkers could be peers, supervisors, or staff. All participants were informed that confidentiality was preserved by using randomly generated codes. Recent research has shown that the diversity of this type of samples can increase the external validity of results (Wheeler, Shanine, Leon, \& Whitman, 2014).

Each participant received an invitation via e-mail, including information about the study, a personal login code, and a link to the online study. After completing the selfassessment, including measurements of psychopathy and interpersonal influence as well as demographic information, employees were asked to enter e-mail addresses of at least two coworkers. Next, co-workers were automatically invited via e-mail to take part in the study; during this phase of the study, information regarding targets' contextual performance and counterproductive work behaviors directed at individuals was collected. Using pseudoanonymized randomized code (German Federal Act of Data Protection, 2010, § 3a), we were able to link target employees' self-assessments with co-workers' ratings while simultaneously granting confidentiality to all participants (i.e., targets and other-raters). 
Of the 523 targets, $281(57 \%)$ completed the self-assessment. The 281 targets invited 854 co-workers to provide observer-ratings for the study. A total of 443 (52\%) co-worker ratings were obtained. Co-workers could only be invited, if targets fully completed the assessment. The quality of the data was checked in several steps. First, to ensure targets had enough experience with their current jobs and could adequately answer all questions, targets with less than six month of job tenure and less than 20 hours of working time per week were excluded. Second, co-workers were asked to report their relationship with the target employee. The choices were peer, staff, supervisor or other. All cases $(N=21)$ where the respondents had no working contact with the target employee were dropped from further analyses. In total, 347 peers, 53 supervisors and 22 staff members took part in the study. Third, all other-raters who had jointly worked together with the target employee for less than six months were dropped in order to preserve the validity of other-ratings $(N=14)$. Fourth, all target cases with less than two other-ratings $(N=100)$ were dropped from further analyses, because, given the nature of counterproductive behavior at work, it is unlikely that one person can observe all possible incidents of interpersonal-directed counterproductive work behavior.

Thus, predictor and criterion data were available for 161 of the 281 original target respondents. The final sample consisted of 161 target-co-workers triads, of which 72 targets were male and 89 targets were female. The mean age of target employees was 42 years $(S D=$ $12.15)$, with mean job tenure of 10 years $(S D=8.91)$, and an average working time of 40 hours per week $(S D=9.7)$. Mean hierarchical position of the target employees within their organizations was $57 \%(0 \%=$ bottom level, $100 \%=$ top level $)$.

Those 161 targets with two other-raters were older $(M=41.48$ years $)$ than those 42 targets with only one $(M=36.74$ years $)$ other rater or those 58 targets with no $(M=34.36$ years $)$ other rater $\left(F(2,258)=8.49, p<.01, \eta^{2}=.06\right)$, and they reported longer job tenure $(F$ $\left.(2,258)=6.18, p<.01, \eta^{2}=.05\right)$. Therefore, we controlled for targets' age and job tenure in the statistical analyses. Additionally, scores in rebellious nonconformity (see the Measures 
section below) were lower in those targets with two other-raters $(M=1.83)$ than in those targets with only one other $\operatorname{rater}(M=1.88)$ or in those targets with no other $\operatorname{rater}(M=1.95 ; F$ $\left.(2,258)=4.41, p<.05, \eta^{2}=.03\right)$. Finally, scores in self-centered impulsivity were lower in those targets with two other-raters $(M=1.84)$ than in those targets with only one other rater $(M=1.87)$ or in those targets with no other rater $\left(M=1.92 ; F(2,258)=3.57, p<.05, \eta^{2}=\right.$ .03). No other group differences in other variables (i.e., interpersonal influence, CWB-I, contextual performance, control variables) including other psychopathy scores (composite score, factors, and scales) were found. As these effect sizes were small $\left(\eta^{2}=.03\right)$, we concluded that there was marginal range restriction in the psychopathy scores in the present sample.

\section{Measures}

Psychopathy (PPI-R). Targets' psychopathic personality dispositions were assessed with the Psychopathy Personality Inventory - Revised (PPI-R; Lilienfeld \& Widows, 2005); the German version has been validated by Alpers and Eisenbarth (2008). Due to its ability to detect relatively mild levels of psychopathy traits in non-forensic samples (Lilienfeld \& Andrews, 1996; Lilienfeld \& Widows, 2005), the PPI-R is a useful assessment tool for individuals in work place settings (Smith \& Lilienfeld, 2013). The measure originally contained 154 items, with 131 items comprising the overall score. We did not collect the additional 23 items assessing virtuous responding because recent research shows that high scores in social desirability scales can actually reflect honest rather than dishonest responding (Zettler, Hilbig, Moshagen, \& de Vries, 2015) indicating unsettled validity.

The substantive PPI-R composite consists of eight subscales comprising two correlated factors (i.e., fearless dominance, self-centered impulsivity; Patrick et al., 2006) and an additional orthogonal facet (Lilienfeld \& Widows, 2005) called the cold-heartedness scale ( $\alpha=.72$; sample item: "When someone is hurt by something I say or do, that's their problem.”). The factor fearless dominance $(\alpha=.85)$ consists of the social influence scale $(\alpha=$ 
.80) assessing manipulative behavior (e.g., "If I really want to, I can persuade people of almost everything."), attention seeking (e.g., "When I meet people, I can often make them interested in me with just one smile."), and low social fear (e.g., "I feel sure of myself when I am around other people."), the fearlessness scale ( $\alpha=.80$; e.g., "It would be fun to fly a small airplane by myself."), and the stress immunity scale ( $\alpha=.83$; e.g., "I don't let everyday hassles get on my nerves."). The factor self-centered impulsivity $(\alpha=.88)$ is composed of the Machiavellian egocentricity scale ( $\alpha=.75$; e.g., "I tell a lot of 'white lies'."), the rebellious nonconformity scale ( $\alpha=.83$; e.g., "I get restless when my life gets too predictable."), the blame externalization scale $(\alpha=.88$; e.g., "A lot of people have tried to 'stab me in the back'."), and the carefree nonplanfulness scale ( $\alpha=.69$; e.g., "I like to act first and think later.”). Target employees provided self-ratings on a four-point Likert-type scale ( 1 = False, 2 = Mostly False, 3 = Mostly True, 4 = True). Cronbach's alpha of the overall psychopathy (PPI-R) composite was $\alpha=.85$.

Interpersonal influence (II). Targets' interpersonal influence was measured with the corresponding four items of the Political Skill Inventory (PSI, Ferris et al., 2005). A validated German translation (Blickle, Kramer, et al., 2011; Lvina et al., 2012) was used. Sample items include: "I am able to make most people feel comfortable and at ease around me", and "I am able to communicate easily and effectively with others". Target employees rated their level of interpersonal influence on a seven-point Likert-type scale $(1=$ Strongly Disagree, $7=$ Strongly Agree). Cronbach's Alpha was $\alpha=.74$.

Interpersonally-directed counterproductive work behavior (CWB-I). Targets' counterproductive work behavior directed at/towards individuals (CWB-I) was assessed by other-raters with the German version (Zettler \& Hilbig, 2010) of Bennett and Robinson's (2000) Workplace Deviance Scale. The measure has been widely used in related research and has proven useful in the context of the dark triad (Judge, LePine \& Rich, 2006). Raters evaluated target employees' CWB-I on rating anchors ranging from (1) “never" to (7) "daily". 
Sample items include: "Made fun of someone at work", "Said something hurtful to someone at work", and "Acted rudely toward someone at work". Due to the aggregation of both otherratings, estimates of inter-rater agreement were computed. The intraclass correlation ICC (1, 1; McGraw \& Wong, 1996) specifies the proportion of variance by differences in targets; for CWB-I, it was .27. The intraclass correlation $\operatorname{ICC}(1, \mathrm{k})$ estimates the stability of mean ratings furnished from $K$ judges (LeBreton \& Senter, 2008); for CWB-I it was .43. Another popular estimate of interrater agreement, $r_{w g}$, can vary between 0 and 1 (LeBreton $\&$ Senter, 2008), with acceptable values above .70 (Lance, Butts, \& Michels, 2006). The mean $r_{w g}$ of the CWBI ratings was .88 , ranging from 0.00 to 1.00 with a median of .99 . Cronbach's alpha reliability of the aggregated measure in the present study was $\alpha=.89$.

Contextual performance (CP). We used a German adaptation (Blickle, Kramer, et al., 2011) of the job performance rating scale by Ferris and colleagues (Ferris, Witt, \& Hochwarter, 2001) to assess contextual performance. Because this job performance scale was originally designed for computer programmers, we followed the approach by Blickle, Kramer, et al. (2011), and used their items that were adapted to be slightly more general and thus more applicable for a broad range of jobs. For example, the item "Responds to calls within minutes when on duty" was adapted to "Responds to queries swiftly." Based on previous research findings (Conway, 1999; van Scotter \& Motowidlo, 1996), the job dedication and interpersonal facilitation items were used to build the contextual performance score. Items were rated on a 5-point scale with the following ratings: 1 (weak or bottom $10 \%$ ), 2 (fair or next $20 \%), 3$ (good or next 40\%), 4 (very good or next $20 \%)$, and 5 (best or top $10 \%)$. Sample items include: "Avoids being late-absent, especially during peak or critical demand" and "Cooperates with other team members by sharing information openly." The intraclass correlation ICC $(1,1)$ was .41 for contextual performance ratings, and the ICC $(1, \mathrm{k})$ was .59 . The mean $r_{w g}$ of the contextual performance ratings was .94 , ranging from 0.00 to 1.00 with a median of .98 . Cronbach's alpha reliability of the aggregated measure in the present study 
was $\alpha=.82$.

Control variables. Previous research has shown gender (Bowen, Swim \& Jacobs, 2000) and age (Waldmann \& Aviolo, 1986) to impact performance ratings. In addition, research has found that males tend to score higher on all three of the dark triad traits (i.e., psychopathy, narcissism, and Machiavellianism; Paulhus \& Williams, 2002). Therefore, gender and age were included as controls. As a proxy for intelligence (cf., Blickle \& Schnitzler, 2010), educational level ranging from (1) left school without graduation to (8) doctoral degree, was included as a control. Additionally, we controlled for working hours per week, years of job tenure, and hierarchical position, because employees were sampled from a broad range of jobs (Momm et al, 2015).

\section{Statistical Analyses}

Test of normal distribution. Due to target employees nominating which other-raters would assess them, there was a probability of selection bias. If there was a selection bias, the distribution of the contextual performance scale would have been skewed. Therefore we examined the distribution of the contextual performance scale. Zero values of skewness and kurtosis represent a perfectly normal distributions, whereas skewness $> \pm 2$ and kurtosis $> \pm 7$ are indicative of non-normal distributions (Curran, West, \& Finch 1996). Nonetheless, the scores for contextual performance were normally distributed $($ skewness $=-.80$, kurtosis $=.53$; Curran et al., 1996), and thus do not indicate any selection bias. Given that counterproductive work behavior is ostensibly a low base-rate phenomena (e.g., Barbaranelli, Fida, \& Gualandri, 2013), we would expect these ratings to be skewed (i.e., non-normal); therefore, we were not able to rely on a test of normal distribution to glean information pertaining to whether the ratings of CWB-I were possibly affected by a selection-bias. Indeed, in line with recent metaanalytic findings (Greco, O'Boyle \&Walter, 2015), we found a hyperbolic distribution of the other-ratings of CWB-I with a high frequency for rare incidents of CWB-I.

Additionally we examined the distributions for psychopathy. All facets, subfactors, 
and the overall scores were normally distributed, with a skewness ranging between -.22 and .78 , and a kurtosis ranging between -.78 and 1.5 . Interpersonal influence also was normally distributed (skewness $=-.73$, kurtosis $=1.28)$.

Testing discriminant validity of interpersonal influence. Before testing the final measurement models (i.e., those containing only those variables included in our substantive statistical analyses), we felt it was necessary to empirically distinguish the social influence sub-dimension of the fearless dominance scale from the interpersonal influence dimension of the political skill inventory $(r=.58, p<.01)$. Conceptually, the psychopathy scale of social influences assesses manipulative behavior, seeking and getting attention by others, and low shyness and social anxiety (Lilienfeld \& Widows, 2005). Interpersonal influence, by contrast, refers to a subtle, yet convincing rapport-inducing personal style that allows individuals to adapt their behavior in situationally appropriate and influential way (Ferris et al., 2005, 2007).

Empirically, results from confirmatory factor analyses utilizing Mplus 7.0 (Muthén \& Muthén, 1998-2012) support the distinctiveness of the two constructs. First, we compared a one-factor model comprised of odd and even parcels (Little, Cunningham, Shahar, \& Widaman, 2002) of the social influence and interpersonal influence scales $\left(X^{2}(2)=37.86, p<\right.$ .01) with a two-factor model in which interpersonal influence and social influence constructs were modeled as separate factors $\left(X^{2}(1)=1.03, n s\right)$. The change in chi-square (i.e., $\Delta X^{2}(1)=$ $36.83, p<.0001)$ indicated that the two-factor model was significantly superior to the onefactor model. Based on the estimates from the CFA, we calculated the average variance extracted (AVE) for both constructs. An AVE greater than .50 provides evidence of a construct's convergent validity (Fornell \& Larcker, 1981). The AVE values were .69 for interpersonal influence and .82 for social influence. Further, evidence of discriminant validity is present when the AVE of both constructs is greater than the shared variance (i.e., the squared correlation) between constructs (Fornell \& Larcker, 1981). The squared correlation between interpersonal influence and social influence was .48, thereby providing strong 
evidence of distinctiveness of the two scales.

Final measurement models. To evaluate the independence and distinctiveness of the final measurement models, we conducted a number of confirmatory factor analyses in Mplus 7.0 (Muthén \& Muthén, 1998-2012; van der Sluis, Dolan, \& Stoel, 2005). Prior to testing the models, we computed two indicators grouping the odd-and even-numbered items of our measures (Little et al., 2002). Occurring Heywood-cases were solved by setting the respective residual variance to zero (Dyer, Hanges, \& Hall, 2005). In the first model, the self-ratings by targets (fearless dominance, self-centered impulsivity, cold-heartedness, and interpersonal influence) were modeled as one factor, and the aggregated other-ratings (CP and CWB-I) were modeled as a second factor. The fit indices of this model were unsatisfactory: $(\chi 2=$ 599.77, $d f=53, p<.01, R M S E A=.253, C F I=.406, S R M R=.162)$. In the second model, each construct was modeled as a separate factor. Fit indices for this model were satisfactory $\left(\chi^{2}=96.70, d f=41, p<.01, R M S E A=.092, C F I=.939, S R M R=.062\right)$ and demonstrated a significantly better model fit than the first model $(\Delta \chi 2=503.07, \Delta d f=12, p<.01)$.

Finally, we compared two different models with the overall aggregate measure of psychopathy. In the first model, self-ratings by targets (i.e., psychopathy and interpersonal influence) were modeled as one factor, and aggregated other-ratings (CP and CWB-I) were modeled as a second factor. The fit indices of this model were unsatisfactory $\left(\chi^{2}=324.55, d f\right.$ $=20, p<.01, R M S E A=.308, C F I=.526, S R M R=.156)$. In the second model, one factor for each construct was modeled. Fit indices were satisfactory: $(\chi 2=11.11, d f=16, p=.80$, RMSEA $=.000, C F I=1.000, S R M R=.039)$ and indicated that the second model fit significantly better than the first model $(\Delta \chi 2=313.43, \Delta d f=4, p<.0001)$. In sum, these results support the distinctiveness and uniqueness of the scales used to operationalize the constructs of interest.

Hypothesis testing. Based on Cohen, Cohen, West, and Aiken (2003), hierarchical (moderated) regression analyses were conducted to test our hypotheses. All of the predictor 
variables were centered prior to analyses. For each criterion of interest, multiple sets of hierarchical regression analyses were conducted. First, the psychopathic personality dimensions (i.e., cold-heartedness, self-centered impulsivity, fearless dominance) and interpersonal influence main effects were included as predictors of CWB-I (Model 1a) and CP (Model 2a). Next, consistent with Dawson's recommendations (2014), we included the squared main effect terms as predictors of CWB-I (Model 1b) and CP (Model 2b) in order to account for the possibility of nonlinearity. Subsequently, the pure interaction model without any control variables was tested in line with Becker (2005) who cautioned that control variables may hamper analyses by unnecessarily soaking up degrees of freedom and may bias the findings related to the hypotheses. As such, the fearless dominance $\mathrm{x}$ II interaction term was added as a predictor of CWB-I and CP (Models 1c and 2c, respectively). Finally, following recommendations by Bono and McNamara (2011), all control variables were included in Models 1d and 2d.

To further evaluate our results, we also analyzed the interaction between the overall PPI-R score and interpersonal influence without controls (Models 1e and 2e) and with control variables (Models 1f and 2f). To determine the effect sizes of our interactions, we computed Cohen's $f^{2}$ (Cohen et al., 2003). Significant interactions were plotted using guidelines by Cohen et al. (2003) and Hayes (2013). In addition we also computed regions of significance (Johnson-Neyman-technique; Hayes, 2013).

\section{RESULTS}

Table 1 presents the means, standard deviations, correlations, and internal consistency reliability estimates of study variables. Other-reports of CWB-I and CP were negatively related $(r=-.25, p<.01)$, mirroring previous results that these constructs are related yet distinct (Carpenter, Berry, \& Houston, 2014). 
The complete hierarchical moderated regression analyses for CWB-I and CP can be found in Tables 2 and 3, respectively. The bivariate correlations (Table 1) indicate that selfcentered impulsivity was positively associated with other-reported CWB-I $(r=.29, p<.01)$ and CP $(r=-.16, p<.05)$, respectively. Moreover, in all four models (Table 2, Models 1a-1d), self-centered impulsivity had a significant positive impact on other-rated CWB-I $(.25 \leq \beta \leq$ .30 , all $p<.01$ ). In addition, in all four models (Table 3, Models 2a-2d), self-centered impulsivity had a significant negative impact on other-rated $\mathrm{CP}(-.20 \leq \beta \leq-.16$, all $p<.05)$. Therefore, the main effects of self-centered impulsivity on both CWB-I (H1) and CP (H2) were supported.

Further, we argued that interpersonal influence would be negatively related to otherrated CWB-I (H3) and positively related to $\mathrm{CP}(\mathrm{H} 4)$. The bivariate correlations (Table 1) indicated that interpersonal influence was not associated with other reported CWB-I $(r=-.06$, $n s)$ or other-rated CP $(r=-.01, n s)$. Similarly, regression analyses indicated that interpersonal influence predicted neither CWB-I (Table 2, Model 1a; $\beta=-.06, n s$.) nor CP (Table 3, Model $2 \mathrm{a} ; \beta=-.02, n s)$. However, further analyses revealed that interpersonal influence had a significant curvilinear effect on other-rated CWB-I (Model $1 \mathrm{~b} ; \beta=.16, p<.10$ ). This curvilinear finding is discussed in greater detail in the online supplemental materials. Taken together, we failed to find support for Hypotheses 3 and 4.

In line with Hypothesis 5, the interaction term of fearless dominance x II on CWB-I was significantly negative $(\beta=-.34, p<.01)$ and accounted for $8 \%$ additional variance in the criterion (see Table 2, Model 1c). The interaction term was still significant $(\beta=-.31, p<.01)$ even when including the control variables in Model 1d. Cohen's $f^{2}$ indicated a moderate effect without control variables $\left(f^{2}=.09\right)$ and a small to moderate effect with control variables $\left(f^{2}=\right.$ .06). According to Cohen et al. (2003), the interaction was plotted at one standard deviation above and below the mean of interpersonal influence. The form of the interaction is displayed 
in Figure 1.

Insert Figure 1 about here

As expected, for target employees low in II (i.e., $1 S D$ below mean), higher levels of fearless dominance were associated with higher levels of other-rated CWB-I $(b=1.12, p<$ .01 ), whereas for target employees high in II (i.e., $1 S D$ above mean), fearless dominance was not related to CWB-I $(b=-.51, n s)$. We also computed the regions of significance (JohnsonNeyman technique; Hayes, 2013). For centered II values below -.14 and above 1.06, the relation between fearless dominance and CWB-I becomes significant. Additionally, all three scales (i.e., social influence, fearlessness, and stress immunity) constituting fearless dominance showed the same significant pattern of interaction with interpersonal influence. Thus, empirical findings fully supported Hypothesis 5. Moreover, we also examined the data by including all targets with only one other-rater $(N=201)$ and found that the results remained consistent as compared to the sample with both other-raters $(N=161)$.

In addition, we tested the interactive effects of II and both the overall PPI-R score and the remaining PPI-R facets (cold-heartedness and self-centered impulsivity) on CWB-I. Results indicated that the cold-heartedness and self-centered impulsivity facets did not significantly interact with II to predict CWB-I (see online supplemental materials for more details). However, overall PPI-R did significantly interact with II to predict CWB-I (Table 2 Model 2f). The form of the interaction resembled that of the fearless dominance $\times$ II interaction which can be seen in Figure 1.

Finally, in line with Hypothesis 6, the interaction term of fearless dominance x II significantly predicted CP $(\beta=.20, p<.05)$, and accounted for $3 \%$ additional variance explained in contextual performance (see Table 3, Model 2c). Control variables did not impact the significance of the interaction term (Model 2d; $\beta=.21, p<.05$ ). Cohen's $f^{2}$ 
indicated a small effect with and without control variables $\left(f^{2}=.03\right)$. The form of the interaction can be found in Figure 2. As expected, for low levels of II (i.e., $1 S D$ below mean), there was a negative relation between fearless dominance and contextual performance $(b=-$ $.56, p<.05)$. Contrarily, when II was high (i.e., $1 S D$ above mean), no relation between fearless dominance and contextual performance was detected $(b=.53, n s)$. The JohnsonNeyman region of significance indicated that for centered II values below -.73 and above 1.04, the relation between fearless dominance and CP becomes significant. Thus, our empirical findings fully supported Hypothesis 6.

Insert Figure 2 about here

Again, we examined the interactive effects of II and both the overall PPI-R score and the remaining PPI-R facets (cold-heartedness and self-centered impulsivity) on CP. Results indicated that the cold-heartedness and self-centered impulsivity facets did not significantly interact with II to predict CP (see online supplemental materials for more details). However, overall PPI-R did significantly interact with II to predict CP (Table 3, Model 2e). The form of the interaction resembled that of the fearless dominance $\times$ II interaction which can be seen in Figure 2. Although not hypothesized, we found a significant curvilinear effect of coldheartedness on CP (see Table 3, Model $2 \mathrm{~b}, \beta=-.24, p<.01$ ). As online supplementary materials indicate, the relation between cold-heartedness and other-rated $\mathrm{CP}$ demonstrated an inverted $u$-shaped form, with people possessing medium to high levels of $\mathrm{CH}$ showing the most CP. Once again, we examined the data by including all targets with only one other-rater $(N=201)$; with the exception of the curvilinear effect of cold-heartedness that scarcely failed significance $(p=.052)$, the results remained consistent as compared to the sample with both other-raters $(N=161)$. 


\section{Contributions to Theory and Research}

The purpose of this study was to examine the relations of the individual dimensions of psychopathic personality trait with constructive (i.e., contextual performance, CP) and destructive (i.e., interpersonally-directed counterproductive work behavior, CWB-I) interpersonal performance behaviors. In doing so, we hoped to explain some of the underwhelming effect sizes of the relations with aggregate psychopathic personality and workplace performance behaviors identified by O'Boyle and colleagues (2012). We argued that self-centered impulsivity, characterized by impulsivity, irresponsibility, and instant need satiation (Cleckley, 1988; Hare, 1999) would be related to heightened CWB-I and lower levels of CP, whereas cold-heartedness, an affective deficiency (Cleckley, 1988; Hare, 1999), would not be related to these performance behaviors. Finally, we argued that individuals high in fearless dominance are driven by a strong, ruthless, and unscrupulous desire to get ahead, which, if unbalanced, would be pursued at the expense of peripheral others' best interests. However, socioanalytic theory suggests that individuals who are socially skilled will adjust their behavior based on what is situationally appropriate (Hogan \& Shelton, 1998). Interpersonal influence equips individuals with a behavioral flexibility that allows them to develop good rapport with others via their subtle, unassuming, and effective communication style and ability to behave in the most situation-specific, appropriate, and influential way (Ferris et al., 2007); thus, individuals with high levels of interpersonal influence were thought to be better able to pursue their motives to get ahead without being perceived as engaging in negative interpersonal behaviors such as CWB-I or the withholding of contextual performance.

Results lent strong support for our hypotheses. Specifically, self-centered impulsivity was positively and significantly related to others' ratings of interpersonally-directed counterproductive work behaviors (CWB-I), and was significantly negatively related to otherrated $\mathrm{CP}$. Additionally, while the main effects of interpersonal influence and fearless 
dominance were not significant predictors of CWB-I or CP, the interaction of these constructs significantly predicted the criterion of interest. Specifically, as hypothesized, high levels of fearless dominance and interpersonal influence were associated with significantly less undesirable interpersonal performance (CWB-I). Contrarily, high levels of fearless dominance combined with low levels of interpersonal influence were associated with significantly less desirable interpersonal performance behaviors (CP). Finally, while we did not formally hypothesize the null effect, as expected, results did support the notion that the affective deficiency characterizing the cold-heartedness dimension of psychopathic personality was not significantly related to the interpersonal performance behaviors of interest.

Interestingly, while we did not find support for the main effect of interpersonal influence on CWB-I (H3) or CP (H4), we did detect a significant u-shaped curvilinear association between interpersonal influence and CWB-I. Following Le and colleagues (Le et al., 2011), we computed the inflection point $\left(\mathrm{II}_{\text {inflection }}=-.05\right)$, which describes a standardized score that reflects the value of II where the relation between II and CWB-I starts changing direction. The form of this curvilinear relation can be seen in online supplementary materials. Accordingly, results indicated that employees with low and high levels of (self-reported) interpersonal influence were rated by others as most engaged in interpersonally counterproductive activities.

More specifically, low levels of interpersonal influence were associated with heightened levels of CWB-I. This finding is consistent with the view that low skill in establishing good rapport with others and inability to adapt one's behavior to what is situationally effective would be linked to inappropriate interpersonal behavior. On the other hand, moderate levels of interpersonal influence were associated with the lowest levels of CWB-I. Finally, high levels of interpersonal influence were also associated with more CWBI. One reason for this could be that individuals who rate themselves as in possession of high levels of interpersonal influence may be especially off-putting. For instance, in efforts to 
establish good rapport with some individuals, employees might make fun of, or say something disrespectful to others. Indeed, corresponding findings have been found in the school context, indicating that students low and high in perceived popularity tend to behave more aggressively towards others than those with intermediate perceived popularity (De Bruyn, Cillessen, \& Wissink, 2010; Walcott, Upton, Bolen, \& Brown, 2008).

Finally, we did also find a curvilinear relation between cold-heartedness and CP, though in an inverted u-shaped manner. That is, intermediate levels of cold-heartedness were associated with highest contextual performance ratings by others, whereas (especially) low and high levels of cold-heartedness, respectively, were related to less CP. Interestingly, a similar pattern has been found recently for the relation between Machiavellianism and different forms of organizational citizenship behavior (OCB; Zettler \& Solga, 2013). These results might be interpreted similarly as cold-heartedness shares some characteristics with Machiavellianism (e.g., callousness or ruthlessness towards others; e.g., Furnham, Richards, \& Paulhus, 2013) and CP shows some overlap with OCB (e.g., Motowidlo \& Kell, 2012). More specifically, more moderate levels of psychopathic personality traits may be beneficial in today's organizations as employees need and want to gain support from others, secure their interests in negotiations, and promote their individual interests (Zettler \& Solga, 2013).

Taken together, this study provides a few notable contributions to both the psychopathic personality and political skill literatures. First, this is one of the first studies to examine employees' psychopathic personality trait within a real workplace setting. This is an important contribution as most of the research on psychopathic personality has been conducted within forensic settings (e.g., utilizing incarcerated prisoners, psychiatric patients; Cooke \& Michie, 2001), via designs employing students (e.g., Baysinger et al., 2014), or has employed meta-analytic techniques to summarize findings from past "Dark Triad" studies largely examined within non-representative populations (e.g., military personnel, police officers; O’Boyle et al., 2012). 
Relatedly, we examined the different dimensions of psychopathic personality trait tendencies and their relations with workplace behavior. As expected, self-centered impulsivity was strongly related to undesirable workplace behaviors including high levels of CWB-I and low levels of CP. Fearless dominance was only related to negative workplace behaviors when individuals lacked an important social skill, namely interpersonal influence. Therefore, these findings contribute to the psychopathic personality literature in that they provide support for the notion that the fearless dominance, self-centered impulsivity, and cold-heartedness dimensions of psychopathic personality manifest themselves differently in the workplace. Unexpectedly, cold-heartedness was related to CP in an inverted u-shaped manner. This is especially informative in light of the lackluster meta-analytic estimates of the relations of (aggregate) psychopathic personality with job performance and counterproductive behaviors (O’Boyle et al., 2012).

Along these lines, this study contributes to the political skill literature in that findings provide support for the marked effect of a facet of political skill one one's own self, as well as how peripheral others experience or perceive politically skilled persons (Ferris et al., 2007; Ferris et al., 2012). More importantly, this study contributes to the political skill literature in that we examine one particular dimension of political skill, namely interpersonal influence, as a type of social skill that allows individuals high in fearless dominance to more effectively package their agentic desires in order to better get along. In doing so, this manuscript answers calls for research examining how the dimensions of political skill differentially affect workplace outcomes (Ferris et al., 2012) and contributes to the limited body of research that has begun to do so (e.g., Wihler et al., 2014).

Finally, this study provides additional support for socioanalytic theory in that results indicate that those individuals who are socially skilled are more capable of translating their basic motives (i.e., to get ahead) into purposeful and more importantly, successful action (Hogan \& Shelton, 1998). Additionally, this research also demonstrates that the basic tenets 
of socioanalytic theory hold true even for individuals characterized by some of the more aberrant personality traits, and extends this research to examine social competencies as capable of attenuating maladaptive behavior.

\section{Practical Implications}

These findings present practical implications with regards to selection, training and development, and performance management. Most notably, while we found that interpersonal influence helps individuals with high levels of fearless dominance to effectively package such tendencies, we still would suggest that on the whole, high levels of psychopathy are not desirable employee characteristics. For instance, while cold-heartedness was related to the interpersonal performance behaviors in an inverted u-shaped manner, from an employee morale standpoint, most organizations should benefit (e.g., from greater affective commitment, social support, etc.) when their employees show care and concern for others. However, in certain occupations, positions, and/or at certain hierarchical levels, some tendencies associated with psychopathic personality may be very useful (Dutton, 2012). For instance, in occupations that require composure under pressure and/or quick and decisive action, individuals with higher levels of cold-heartedness may be better able to make hard decisions (e.g., those involving employees' employment status). Contrarily, those individuals demonstrating high levels of self-centered impulsivity and cold-heartedness may be especially ill-suited for positions that require patience and thoughtful action, interpersonal sensitivity, and compassion (e.g., nursing). Therefore, we would suggest that organizations consider screening on psychopathic personality trait components when hiring for certain positions in which the possession of these tendencies would be especially detrimental.

From a legal standpoint, it is important to note that (at least in the United States), it is illegal for organizations to discriminate against workers on the basis of a disability. Psychopathic personality, however, has never been classified as a disorder (cf. American Psychiatric Association, DSM 5, 2013). Moreover, we are advocating that organizations may 
be interested in identifying the 5 to $10 \%$ of the population with subclinical psychopathic personality tendencies who are most likely to be capable of functioning in a work setting. Individuals who have sub-clinical psychopathic personality tendencies have similar personality profiles as those individuals with clinical psychopathic personality tendencies, but at less extreme levels (Hall \& Benning, 2006; LeBreton et al., 2006). This distinction allows organizations to avoid any potential complications associated with using personality inventories (e.g., PPI-R) as a part of pre-employment questionnaires.

Nonetheless, the use of personality inventories to identify individuals with clinical levels of psychopathic personality traits would be considered a violation of the American's with Disabilities Act (ADA) of 1990 (amended in 2008), because the survey would be considered a pre-employment medical screening (Wu \& LeBreton, 2011). Therefore, it is critical that organizations who wish to screen for these tendencies during the hiring process utilize an appropriate instrument for doing so, because some psychopathic personality inventories have been purposed and validated as clinical screening tools (e.g., Psychopathy Checklist-Revised [PCL-R], Hare, 2003). The assessment tool used in this study to assess psychopathic personality tendencies, the PPI-R, is a validated instrument for capturing subclinical levels of these tendencies. Therefore, the use of the PPI-R and other subclinical inventories to capture psychopathic personality tendencies would be defensible under the ADA whereas the use of clinically-oriented inventories would likely violate the ADA.

Further, while personality is sometimes considered innate and unmalleable, social skills are thought to be trainable (Hogan \& Shelton, 1998). Thus, findings from this study also have implications from a training and development standpoint. For existing employees found to be in possession of any of the psychopathic personality tendencies, it may be beneficial to provide them with opportunities to train and develop interpersonal influence skills as well as other skills captured under the aggregate political skill competency. Such training could include exercises to emphasize the importance of building rapport with coworkers, increase 
behavioral flexibility, develop employees' own self-awareness, gain an understanding of how a target employee is perceived by others, and to demonstrate empathy and concern for others. Such training could contribute to a more positive work environment. Moreover, it's important to point out that regardless of whether individuals exhibit higher levels of psychopathic tendencies or not, political skill in the aggregate (Munyon et al., in press) and interpersonal influence (Wihler et al., 2014) both have a remarkable impact on organizational outcomes for those in its possession and peripheral others. Therefore, from a practical standpoint, organizations may benefit from incorporating political skill training into existing leadership development and fast-tracked employee development programs.

With that being said, because CWB-I was measured via peer reports, there exists a possibility that political skill might help conceal the deviant acts of those individuals with elevated levels of fearless dominance. If this were the case, one could view fearless dominance as the penchant to engage in destructive acts and interpersonal influence as the means to go about doing so undetected; subsequently, training individuals high in fearless dominance to be more interpersonally influential would disrupt the social climate of the organization and impede organizational members from accomplishing tasks. However, note that CWB-I typically takes place in public as it comprises behavior towards others. Of course, some deviant acts related to CWB-I such as playing a mean prank on someone can also be done in private, but most behavior in the realm of CWB-I includes interactions with at least one other person (e.g., cursing at someone, publicly embarrassing someone, saying something hurtful to someone; $c f$. Bennett \& Robinson, 2000). Thus, by focusing on CWB-I, we mitigated the concern that high levels of interpersonal influence help those high in fearless dominance to "successfully hide" their counterproductive acts instead of shaping behavior in a more socially manner. However, even in case that high levels of interpersonal influence help those high in fearless dominance to disguise their destructive acts (which seems relatively unlikely with regard to CWB-I), it is likely that at least some coworkers would eventually 
take notice. Thus, future longitudinal research should explore this possibility.

Finally, from a performance management system, organizations might consider redesigning their reward systems so that in addition to task performance, behaviors that support the social context in which task performance takes place (i.e., contextual performance) are formally rewarded. Reward systems that emphasize other-serving behaviors not only would acknowledge truly altruistic "good citizens," but they might also entice other individuals with less genuine motives to engage in behaviors that support the health and vibrancy of the social context in which work gets done. Specifically, we would argue that individuals with elevated levels of fearless dominance might view contextual performance as a way to further their self-interests if engaging in these constructive interpersonal performance behaviors was formally rewarded by their employer. Performance management systems designed as such would stand to benefit employees (e.g., by expanding the ways they can contribute meaningfully to the organization) as well as the employing organization (e.g., increased morale).

\section{Strengths and Limitations}

Importantly, our findings should be interpreted with careful consideration of the following strengths and weakness. In terms of strengths, several aspects warrant trust in the observed findings. First, we employed a multi-source design in which independent variables were collected from focal individuals and criterion variables were collected from two observers (e.g., coworkers, supervisors). Consistent with recommended practice, we asked observers to provide ratings of targets' CWB-I, as doing so helps to rule out common method bias (Fox, Spector, Goh, \& Bruursema, 2007). Moreover, we felt that such individuals were well suited to validly assess the incidence of targets' CWB-I, because they were in close contact with targets and had worked together for at least 6 months. This should have helped us to at least mitigate common issues that arise with CWB research, such as low base rates (Barbaranelli et al., 2013) and range restriction (Greco et al., 2015). 
In addition, participants were ensured that the ratings that they would be asked to provide would have no impact on job decisions. As indicated by Podsakoff, MacKenzie, and Podsakoff (2012), these assurances likely increased individuals' motivation to respond accurately. Additionally, the multi-source research design provided researchers some assurance that study findings were not due to common method bias. A related strength concerns the strong interrater agreement among observers' ratings of target individuals' interpersonally-directed counterproductive work behaviors and contextual performance. In addition, given that target individuals nominated those individuals who provided the "otherratings," we were concerned about the possibility of a selection bias. However, where possible, we explicitly tested for skewness and kurtosis of the scales as well as for the appropriateness to consider them independently; results indicated that our data were not particularly biased in any way. Finally, the inclusion of the quadratic main effects as control variables when testing interaction effects represents a notable strength, as Dawson (2014) suggested that failure to account for the non-linear main effects could result in falsely detected moderation especially when the independent and moderator variables are correlated.

In light of these strengths, we also wish to point out some notable limitations. Namely, despite being collected from multiple sources, the data are cross-sectional; therefore, we were unable to draw causal inferences from study findings. Additionally, the other-ratings were predominantly provided by target individuals' peers (i.e., $N=275$ ) as opposed to supervisors $(N=43)$. Collecting data from other vantage points (e.g., staff) may reveal that certain raters experience interactions with individuals with elevated levels of psychopathy differently than others. Another limitation is the interrater reliability (ICC $[1, \mathrm{k}]$ ) of $\mathrm{CWB}-\mathrm{I}$ is below the recommended threshold of .70 (LeBreton \& Senter, 2008), indicating a rather low level of agreement among others' ratings of focal individuals' CWB-I. However, our results remained the same regardless of whether we included data of only one other-rater or both other-raters of CWB-I. Given the nature of the construct, it is unlikely that one person can observe all 
possible incidents of interpersonal-directed counterproductive work behavior. For instance, it is quite possible that employees target counterproductive work behaviors toward certain, but not all, coworkers. Therefore, we believe that the use of two other-raters provides a more valid picture of focal individuals' interpersonal-directed counterproductive work behavior.

In addition, a limitation of this study deals with our inability to collect data on the other components of the dark triad, Machiavellianism and narcissism. However, we were concerned that doing so may have provided respondents with sufficient information to infer the purpose of the study. Therefore, out of concerns for validity, in light of the tradeoff between survey length and respondent fatigue, and the empirical evidence that suggests these constructs are related, but distinct (O’Boyle et al., 2012; Wu \& LeBreton, 2011), we chose not to collect data on Machiavellianism and narcissism. Finally, data were collected in the German work force; while the German culture is similar in some regards to other Western cultures (Erez, 2011), the generalizability of these findings to other cultures is tentative pending additional research.

\section{Directions for Future Research}

There exist numerous opportunities for future research, especially with regard to psychopathic personality trait at work. First and foremost, this research examined only two types of performance: (interpersonally-directed) counterproductive work behavior and contextual performance. However, it would be interesting to examine whether the fearless dominance $\times$ interpersonal influence interaction is consistent across sales and other sorts of performance domains. Moreover, what other social competencies may help individuals with psychopathic personality tendencies to package and pursue their motives more successfully? Contrarily, are there individual differences (e.g., organizational cynicism, hostile attribution bias) that amplify the deleterious effects of psychopathic personality tendencies?

Additionally, future research should more closely examine the relation between interpersonal influence and CWB-I. While we failed to find support for the hypothesized main 
effect of interpersonal influence on CWB-I, results did indicate the presence of a u-shaped curvilinear association between the two variables. Therefore, more precise theoretical development is needed with regard to the relation between interpersonal influence and CWBI. Moreover, additional empirical examinations need to be conducted in order to determine if the curvilinear effect that was detected is generalizable to other samples or if the finding is specific to these data. Recently curvilinear relations have not only received increased attention in the management literature in general (e.g., Blickle et al., 2015; Grant \& Schwartz, 2011), but also with regard to political skill in particular (Zettler \& Lang, 2015).

In addition, recent research examining leadership from a socioanalytic perspective found that politically skilled leaders who desired to get ahead engaged in more structuring behaviors which in turn were related to followers' satisfaction and institutional effectiveness (Ewen et al., 2013). Along these lines, it would be interesting to examine the mediating mechanisms through which the interactive effects of fearless dominance and interpersonal influence engender effective and/or constructive organizational behavior. Additionally, it would be interesting to examine the affective workplace experiences of the individuals high in psychopathic personality trait tendencies. Do individuals with elevated levels of psychopathy experience job satisfaction or do they only experience satisfaction by pursuing self-interests? Can and will individuals with elevated levels of psychopathy demonstrate high levels of work engagement and if so, under what conditions? Relatedly, within the workplace, are there certain contexts that we find individuals with psychopathic personality tendencies selfselecting into and subsequently thriving in? For instance, perhaps individuals with more elevated levels of psychopathic personality tendencies seek out the uncertainty and ambiguity characteristic of highly political organizations as such contexts provide them with more opportunities to pursue self-interest and amoral conduct.

Further, while the current research relied primarily on peers' (e.g., coworkers) ratings of targets, future research should examine targets' psychopathic tendencies from other 
individuals' perspectives (e.g., auxiliary staff, subordinates, and customers). Individuals with elevated levels of psychopathy may be perceived differently by other individuals based on the perceived power differential, perceived distance, and relational demography between the target and the observer. For instance, future research should examine whether and why individuals with psychopathic personalities may be better suited to exploit auxiliary staff members and individuals lower in the organizational hierarchy. From the criminal research on psychopathy, evidence suggests that individuals with clinical levels of psychopathy are able to pinpoint and exploit more vulnerable targets (Wheeler, Book, \& Costello, 2009). However, in the workplace, little is known about what those individuals with elevated levels of psychopathy actually do within the confines of the organization to exert influence over others. Additionally, it would be interesting to examine subordinates' perspectives of supervisors with elevated levels of psychopathy. For instance, one of the most polarizing, yet widely effective leaders was Steve Jobs, who embodied the quintessential psychopathic dichotomy: cunning and seductive, yet ruthless, lacking empathy, and hostile (Dutton, 2012). How does one reconcile psychopathic personality within the context of leadership? Are the dimensions of political skill the key differentiating factor here as well? Future research should examine this possibility as well as other implications of leaders with elevated levels of psychopathic tendencies. Another interesting direction for future research involves the quality of relationships between individuals with psychopathic tendencies and their co-workers. ${ }^{2}$ For example, it might be interesting to investigate the closeness of relationships (and the resulting number of peer-responses) as well as the lunchtime (e.g., combined breaks) or leisure time behavior of employees with elevated levels of psychopathic personality tendencies. As is apparent, there exist numerous opportunities to examine psychopathy within the organizational sciences.

\section{Conclusion}

The purpose of this study was to examine how the different dimensions of 
psychopathic personality differentially relate to two types of interpersonal performance, counterproductive work behavior directed at individuals (CWB-I) and contextual performance (CP). The self-centered impulsivity dimension of psychopathy was associated with greater instances of other-rated CWB-I and fewer instances of other-rated CP; cold-heartedness, the deficient affective experience associated with psychopathy, unexpectedly was related to $\mathrm{CP}$ in an inverted u-shaped manner. Finally, grounded in socioanalytic theory (Hogan \& Shelton, 1998), we found that individuals who were both high in the fearless dominance dimension of psychopathic personality and highly interpersonally influential engaged in significantly less interpersonal-directed counterproductive work behaviors. Contrarily, individuals engaged in significantly less CP when they indicated high levels of fearless dominance and low levels of interpersonal influence. In light of these findings, we hope that this study spurs continued research regarding subclinical levels of psychopathic personality at work. We encourage researchers to continue to examine the manner in which the dimensions of both psychopathic personality and political skill operate differentially within the organizational context. 


\section{REFERENCES}

Alpers, G. W., \& Eisenbarth, H. 2008. PPI-R: Psychopathic personality inventory-revised. Deutsche Version. Göttingen: Hogrefe.

American Psychiatric Association. 2013. Diagnostic and Statistical Manual of Mental Disorders (5th ed.). Arlington, VA: American Psychiatric Publishing.

Babiak, P., \& Hare, R. D. 2006. Snakes in suits: When psychopaths go to work. New York, NY: HarperCollins.

Barbaranelli, C., Fida, R., \& Gualandri, M. 2013. Assessing counterproductive work behavior: A study on the dimensionality of Cwb-Checklist. Testing, Psychometrics, Methodology in Applied Psychology, 20: 1-15.

Baysinger, M. A., Scherer, K. T., \& LeBreton, J. M. 2014. Exploring the disruptive effects of psychopathy and aggression on group processes and group effectiveness. Journal of Applied Psychology, 99: 48-65.

Becker, T. E. 2005. Potential problems in the statistical control of variables in organizational research: A qualitative analysis with recommendations. Organizational Research Methods, 8: 274-289.

Benning, S. D., Patrick, C. J., Blonigen, D. M., Hicks, B. M., \& Iacono, W. G. 2005. Estimating facets of psychopathy from normal personality traits: A step toward community-epidemiological investigations. Assessment, 12: 3-18.

Bennett, R. J., \& Robinson, S. L. 2000. Development of a measure of workplace deviance. Journal of Applied Psychology, 85: 349-360.

Blickle, G., Fröhlich, J. K., Ehlert, S., Pirner, K., Dietl, E., Hanes, T. J., \& Ferris, G. R. 2011. Socioanalytic theory and work behavior: Roles of work values and political skill in job performance and promotability assessment. Journal of Vocational Behavior, 78: 136148.

Blickle, G., Kramer, J., Schneider, P. B., Meurs, J. A., Ferris, G. R., Mierke, J., Witzki, A. H., 
\& Momm, T. D. 2011. Role of political skill in job performance prediction beyond general mental ability and personality in cross-sectional and predictive studies. Journal of Applied Social Psychology, 41: 488-514.

Blickle, G., Meurs, J. A., Wihler, A., Ewen, C., Merkl, R., \& Missfeld, T. 2015. Extraversion and job performance: How context relevance and bandwidth specificity create a nonlinear, positive, and asymptotic relationship. Journal of Vocational Behavior, 87: 8088

Blickle, G., \& Schnitzler, A. 2010. Is the political skill inventory fit for personnel selection? An experimental field study. International Journal of Selection and Assessment, 18: $155-165$.

Blickle, G., Wendel, S., \& Ferris, G. R. 2010. Political skill as moderator of personality-job performance relationships in socioanalytic theory: Test of the getting ahead motive in automobile sales. Journal of Vocational Behavior, 76: 326-335.

Boddy, C. R. 2006. The dark side of management decisions: Organisational psychopaths. Management Decision, 44: 1461-1475

Bono, J. E., \& McNamara, G. 2011. Publishing in AMJ - Part 2: Research design. Academy of Management Journal, 54: 657-660.

Bowen, C., Swim, J. K., \& Jacobs, R. R. 2000. Evaluating gender biases on actual job performance of real people: A meta-analysis. Journal of Applied Social Psychology, 33: 648-665.

Carpenter, N. C., Berry, C. M., \& Houston, L. 2014. A meta-analytic comparison of self- and other-reported organizational citizenship behavior. Journal of Organizational Behavior, 35: 547-574.

Cleckley, H. M. 1988. The mask of sanity. St. Louis, MO: Mosby. (Original work published in 1941).

Cohen, J., Cohen, P., West, S., \& Aiken, L. 2003. Applied multiple regression/ 
correlation analysis for the behavioral sciences. Mahwah, NJ: Lawrence Erlbaum.

Conway, J. M. 1999. Distinguishing contextual performance from task performance for managerial jobs. Journal of Applied Psychology, 84: 3-13.

Cooke, D. J., \& Michie, C. 2001. Refining the construct of psychopathy: Towards a hierarchical model. Psychological Assessment, 13: 171-188.

Costa, P. T., \& Widiger, T. A. 1994. Personality disorders and the five-factor model of personality. Washington, DC, US: American Psychological Association.

Curran, P. J., West, S. G., \& Finch, J. F. 1996. The robustness of test statistics to nonnormality and specification error in confirmatory factor analysis. Psychological Methods, 1: 16-29.

Dawson, J. F. 2014. Moderation in management research: What, why, when, and how. Journal of Business and Psychology, 29: 1-19.

De Bruyn, E. H., Cillessen, A. H. N., \& Wissink, I. B. 2010. Associations of peer acceptance and perceived popularity with bullying and victimization in early adolescence. Journal of Early Adolescence, 30: 543-566.

Decuyper, M., De Pauw, S., De Fruyt, F., De Bolle, M., \& De Clercq, B. J. 2009. A metaanalysis of psychopathy-, antisocial PD-and FFM associations. European Journal of Personality, 23: 531-565.

Digman, J. M. 1997. Higher-order factors of the Big Five. Journal of Personality and Social Psychology, 73: 1246-1256.

Dutton, K. 2012. The wisdom of psychopaths: What saints, spies, and serial killers can teach us about success. New York, NY: Scientific American.

Dyce, J. A. 1997. The big five factors of personality and their relationship to personality disorders. Journal of Clinical Psychology, 53: 587-593.

Dyer, N. G., Hanges, P. J., \& Hall, R. J. 2005. Applying multilevel confirmatory factor analysis techniques to the study of leadership. The Leadership Quarterly, 16: 149-167. 
Erez, M. 2011. Cross-cultural and global issues in organizational psychology. In S. Zedeck (Ed.), APA handbook of industrial and organizational psychology, vol. 3: 807-854. Washington, DC: APA.

Ewen, C., Wihler, A., Blickle, G., Oerder, K., Ellen, B. P., Douglas, C., \& Ferris, G. R. 2013. Further specification of the leader political skill-leadership effectiveness relationships: Transformational and transactional leader behavior as mediators. The Leadership Quarterly, 24: 516-533.

Ferris, G. R., Blickle, G., Schneider, P. B., Kramer, J., Zettler, I., Solga, J., Noethen, D., \& Meurs, J. A. 2008. Political skill construct and criterion-related validation: A twostudy investigation. Journal of Managerial Psychology, 23: 744-771.

Ferris, G. R., Treadway, D. C., \& Brouer, R. L., \& Munyon, T. P. 2012. Political skill in the organizational sciences. In G. R. Ferris \& D. C. Treadway (Eds.), Politics in organizations: Theory and research considerations: 487-528. New York: Routledge/Taylor \& Francis.

Ferris, G. R., Treadway, D. C., Kolodinsky, R. W., Hochwarter, W. A., Kacmar, C. J., Douglas, C., \& Frink, D. D. 2005. Development and validation of the political skill inventory. Journal of Management, 31: 126-152.

Ferris, G. R., Treadway, D. C., Perrewé, P. L., Brouer, R. L., Douglas, C., \& Lux S. 2007. Political skill in organizations. Journal of Management, 33: 290-320.

Ferris, G. R., Witt, L. A., \& Hochwater, W. A. 2001. Interaction of social skill and general mental ability on job performance and salary. Journal of Applied Psychology, 86: 1075-1082.

Fornell, C., \& Larcker, D. F. 1981. Evaluating structural equation models with unobservable variables and measurement error. Journal of Marketing Research, 18: 39-50.

Fox, S., Spector, P. E., Goh, A., \& Bruursema, K. 2007. Does your coworker know what you're doing? Convergence of self- and peer-reports of counterproductive work 
behavior. International Journal of Stress Management, 14: 41-60.

Furnham, A., Richards, S. C., \& Paulhus, D. L. 2013. The Dark Triad of personality: A 10 Year Review. Social and Personality Psychology Compass, 7: 199-216.

German Federal Act of Data Protection. 2010. Bundesdatenschutzgesetz der Bundesrepublik Deutschland $\S 3$ in der Fassung vom 1.4.2010. Available at http://dejure.org/gesetze/BDSG (accessed June 27, 2014).

Grant, A. M., \& Schwartz, B. 2011. Too much of a good thing: The challenge and opportunity of the inverted U. Perspectives on Psychological Science, 6: 61-76.

Greco, L. M., O’Boyle, E. H., \& Walter, S. L. 2015. Absence of malice: A meta-analysis of nonresponse bias in counterproductive work behavior research. Journal of Applied Psychology, 100: 75-97.

Hall, J. R., \& Benning, S. D. 2006. The "successful” psychopath. In C.J. Patrick (Ed.), Handbook of psychopathy: 459-478. New York, NY: Guilford.

Hare, R. D. 1999. Without conscience: The disturbing word of the psychopaths among us. New York, NY: Guilford.

Hare, R. D. 2003. The Hare psychopathy checklist_revised. Toronto, Canada: Multi-Health Systems.

Harpur, T. J., Hart, S. D., \& Hare, R. D. 1994. Personality of the psychopath. In P.T. Costa \& T. A. Widiger (Eds.), Personality disorders and the five-factor model of personality: 149-173. Washington, DC: American Psychological Association.

Hayes, A. F. 2013. Introduction to mediation, moderation, and conditional process analysis. New York: Guilford Press.

Hogan, J., \& Holland, B. 2003. Using theory to evaluate personality and job-performance relations: A socioanalytic perspective. Journal of Applied Psychology, 88: 100-112.

Hogan, R., \& Shelton, D. 1998. A socioanalytic perspective on job performance. Human Performance, 11: 129-144. 
Judge, T. A., LePine, J. A., \& Rich. B. L. 2006. Loving yourself abundantly: Relationship of narcissistic personality to self- and other perceptions of workplace deviance, leadership, and task and contextual performance. Journal of Applied Psychology, 91: $762-776$.

Kaiser, R. B., LeBreton, J. M., \& Hogan, J. 2015. The dark side of personality and extreme leader behavior. Applied Psychology: An International Review, 64: 55-92.

Lance, C. E., Butts, M. M., \& Michels, L. C. 2006. The sources of four commonly reported cutoff criteria: What did they really say? Organizational Research Methods, 9: 202220.

Le, H., Oh, I.-S., Robbins, S. B., Ilies, R., Holland, E., \& Westrick, P. 2011. Too much of a good thing: Curvilinear relationships between personality traits and job performance. Journal of Applied Psychology, 96: 113-133.

LeBreton J. M., Binning J. F., \& Adorno A. J. 2006. Subclinical psychopaths. In D.L. Segal \& J.C. Thomas (Eds.), Comprehensive handbook of personality and psychopathology, vol. 1: 388-411. New York, NY: Wiley.

LeBreton, J. M., \& Senter, J. 2008. Answers to 20 questions about interrater reliability and interrater agreement. Organizational Research Methods, 11: 815-852.

Lilienfeld, S. O., \& Andrews, B. P. 1996. Development and preliminary validation of a selfreport-measure of psychopathic personality traits in noncriminal populations. Journal of Personality Assessment, 66: 488-524.

Lilienfeld, S. O., \& Fowler, K. A. 2006. The self-report assessment of psychopathy: Problems, pitfalls, and promises. In C. J. Patrick (Ed.), Handbook of Psychopathy: 107-132. New York, NY: The Guilford Press.

Lilienfeld, S. O., \& Widows, M. R. 2005. Psychological assessment inventory-revised (PPIR). Lutz, FL: Psychological Assessment Resources.

Little, T. D., Cunningham, W. A., Shahar, G., \& Widaman, K. F. 2002. To parcel or not to 
parcel: Exploring the question, weighing the merits. Organizational Research Methods, 9: 151-173.

Lvina, E., Johns, G., Treadway, D. C., Blickle, G., Liu, Y., Liu, J., Atay, S., Zettler, I., Solga, J., Noethen, D., \& Ferris, G. R. 2012. Measure invariance of the Political Skill Inventory (PSI) across five cultures. International Journal of Cross-Cultural Management, 12: 171-191.

Lynam, D. R., \& Widiger, T. A. 2007. Using a general model of personality to identify the basic elements of psychopathy. Journal of Personality Disorders, 21: 160-178.

McGraw, K. O., \& Wong, S. P. 1996. Forming inferences about some intraclass correlation coefficients. Psychological Methods, 1: 30-46.

Momm, T. D., Blickle, G., Liu, Y., Wihler, A., Kholin, M., \& Menges, J. 2015. It pays to have an eye for emotions: Emotion recognition ability indirectly predicts annual income. Journal of Organizational Behavior. 36: 147-163.

Motowidlo, S. J., \& Kell, H. J. 2012. Job performance. In I. B. Weiner, N. W. Schmitt, \& S. Highhouse (Eds.), Handbook of Psychology, Volume 12: Industrial and Organizational Psychology ( $2^{\text {nd }}$ ed.): 82-103. New York: Wiley.

Motowidlo, S. J., \& Van Scotter, J. R. 1994. Evidence that task performance should be distinguished from contextual performance. Journal of Applied Psychology, 79: 475480.

Munyon, T. P., Summers, J. K., Thompson, K. M., \& Ferris, G. R. 2015. Political skill and work outcomes: A theoretical extension, meta-analytic investigation, and agenda for the future. Personnel Psychology. 68: 143-184.

Muthén, L. K., \& Muthén, B. O. 1998-2012. Mplus user's guide (7th ed.). Los Angeles, Ca: Muthén \& Muthén.

O'Boyle Jr, E. H., Forsyth, D. R., Banks, G. C., \& McDaniel, M. A. 2012. A meta-analysis of the dark triad and work behavior: A social exchange perspective. Journal of Applied 
Psychology, 97: 557-579.

Patrick, C. J., Edens, J. F., Poythress, N., \& Lilienfeld, S. O. 2006. Construct validity of the PPI two-factor model with offenders. Psychological Assessment, 18: 204-208.

Paulhus, D. L., \& Williams, K. M. 2002. The dark triad of personality: Narcissism, machiavellianism, and psychopathy. Journal of Research in Personality, 36: 556-563.

Podsakoff, P. M., MacKenzie, S. B., \& Podsakoff, N. P. 2012. Sources of method bias in social science research and recommendations on how to control it. Annual Review of Psychology, 63: 539-569.

Schütte, N., Blickle, G. Frieder, R. E., Schnitzler, F., \& Heupel, J. 2015. Political skill moderates the success of psychopaths at the workplace. Paper presented at the annual meeting of the Academy of Management, Vancouver, Canada.

Smith, S. F., \& Lilienfeld, S. O. 2013. Psychopathy in the workplace: The knowns and unknowns. Aggression and Violent Behavior, 8: 204-218.

Van der Sluis, S., Dolan, C. V., \& Stoel, R. D. 2005. A note on testing perfect correlations in EM. Structural Equation Modeling, 12: 551-577.

Van Scotter, J. R., \& Motowidlo, S. J. 1996. Interpersonal facilitation and job dedication as separate facets of contextual performance. Journal of Applied Psychology, 81: 525531.

Walcott, C. W., Upton, A., Bolen, L. M., \& Brown, M. B. 2008. Associations between peerperceived status and aggression in young adolescents. Psychology in the Schools, 45: $550-561$.

Waldman, D. A., \& Avolio, B. J. 1986. A meta-analysis of age differences in job performance. Journal of Applied Psychology, 71: 33-38.

Wheeler, S., Book, A., \& Costello, K. 2009. Psychopathic traits and perceptions of victim vulnerability. Criminal Justice and Behavior, 36: 635-648.

Wheeler, A. R., Shanine, K. K., Leon, M. R., \& Whitman, M. V. 2014. Student-recruited 
samples in organizational research: A review, analysis, and guidelines for future research. Journal of Occupational and Organizational Psychology, 87: 1-26.

Widiger, T. A., \& Trull, T. J. 2007. Plate tectonics in the classification of personality disorder: Shifting to a dimensional model. American Psychologist, 62: 71-83.

Wihler, A., Blickle, G., Ellen, B. P., Hochwarter, W., \& Ferris, G. 2014. Personal initiative and job performance evaluations: Role of political skill in opportunity recognition and capitalization. Journal of Management. DOI: 10.1177/0149206314552451.

Wu, J., \& LeBreton, J. M. 2011. Reconsidering the dispositional basis of counterproductive work behavior: The role of aberrant personality. Personnel Psychology, 64: 593-626.

Zettler, I., \& Hilbig, B. 2010. Honesty-humility and a person-situation interaction at work. European Journal of Personality, 24: 569-582.

Zettler, I., Hilbig, B., Moshagen, M., \& de Vries, R. E. 2015. Dishonest responding or true virtue? A behavior test of impression management. Personality and Individual Differences, 81: 107-111.

Zettler, I., \& Lang, J. W. B. 2015. Employees' political skill and job performance: An inverted u-shaped relation? Applied Psychology: An International Review, 64: 541577.

Zettler, I., \& Solga, M. 2013. Not enough of a "dark" trait? Linking Machiavellianism to job performance. European Journal of Personality, 27: 545-554. 


\section{FOOTNOTES}

1. A different version of this paper has been presented at the 2015 Annual Conference of the Academy of Management (Schuette, Blickle, Frieder, Schnitzler, \& Heupel, 2015). Based on the feedback during the revision process, we made several changes regarding the level of interest of our constructs. Specifically, our previous Hypothesis 1 focused on the relation between global psychopathic personality and overall counterproductive work behavior (comprising CWB-O \& CWB-I). Our new Hypothesis 5 previously focused on the interactive effects of global psychopathic personality and political skill (comprising interpersonal influence, social astuteness, networking ability, and apparent sincerity) on counterproductive work behavior. Finally, our new Hypothesis 6 formerly examined the interactive effects of global psychopathic personality and political skill on adaptive performance.

2. We thank an anonymous reviewer for this suggestion. 
Table 1

Means, Standard Deviations, Alphas, and Study Variable Correlations

\begin{tabular}{|c|c|c|c|c|c|c|c|c|c|c|c|c|c|c|c|c|c|c|c|c|c|c|}
\hline & $M$ & $S D$ & 1 & 2 & 3 & 4 & 5 & 6 & 7 & 8 & 9 & 10 & 11 & 12 & 13 & 14 & 15 & 16 & 17 & 18 & 19 & 20 \\
\hline 1 Gender & 1.45 & .50 & & & & & & & & & & & & & & & & & & & & \\
\hline 2 Age & 41.48 & 12.15 & $.17 *$ & & & & & & & & & & & & & & & & & & & \\
\hline $\begin{array}{l}3 \text { Educational } \\
\text { Level }\end{array}$ & 5.83 & 1.63 & .04 & .01 & & & & & & & & & & & & & & & & & & \\
\hline $\begin{array}{l}4 \text { Working hours } \\
\text { per week }\end{array}$ & 39.81 & 9.70 & $.32^{* * *}$ & -.10 & $.19 *$ & & & & & & & & & & & & & & & & & \\
\hline $\begin{array}{l}5 \text { Job tenure } \\
\text { (years) }\end{array}$ & 10.18 & 8.91 & .14 & $.63^{* * *}$ & -.07 & -.07 & & & & & & & & & & & & & & & & \\
\hline $\begin{array}{l}6 \text { Hierarchical } \\
\text { Position }\end{array}$ & 56.99 & 22.78 & .14 & $.30^{* *}$ & .14 & $.31 * *$ & $.19^{*}$ & & & & & & & & & & & & & & & \\
\hline $\begin{array}{l}7 \text { Fearless } \\
\text { Dominance }\end{array}$ & 2.61 & .37 & .15 & -.15 & -.06 & $.16^{*}$ & $-.22^{* *}$ & .05 & $(.85)$ & & & & & & & & & & & & & \\
\hline $\begin{array}{l}8 \text { Social } \\
\text { Influence }\end{array}$ & 2.72 & .39 & -.04 & -.09 & -.09 & -.02 & -.09 & .05 & $.56^{* *}$ & $(.80)$ & & & & & & & & & & & & \\
\hline 9 Fearlessness & 2.38 & .70 & $.19 *$ & $-.20 *$ & -.06 & $.20 *$ & $-.19 *$ & -.05 & $.82^{* *}$ & .15 & $(.80)$ & & & & & & & & & & & \\
\hline $\begin{array}{l}10 \text { Stress } \\
\text { immunity }\end{array}$ & 2.74 & .45 & .11 & .02 & .01 & -09 & $-.16^{*}$ & .15 & $.70^{* *}$ & $.26^{* *}$ & $.32 * *$ & $(.83)$ & & & & & & & & & & \\
\hline $\begin{array}{l}11 \text { Self-centered } \\
\text { Impulsivity }\end{array}$ & 1.84 & .24 & .06 & -.14 & .02 & .12 & -.02 & -.02 & -.08 & .02 & .08 & $-.35 * *$ & $(.88)$ & & & & & & & & & \\
\hline $\begin{array}{l}12 \text { Machiavellian } \\
\text { Egocentricity }\end{array}$ & 2.09 & .34 & -.05 & $-.20^{*}$ & .14 & .00 & -.05 & -.07 & $-.18^{*}$ & .03 & -.05 & $-.38 * *$ & $.75^{* * *}$ & $(.75)$ & & & & & & & & \\
\hline $\begin{array}{l}13 \text { Rebellious } \\
\text { Nonconformity }\end{array}$ & 1.83 & .34 & .08 & $-.22 *$ & .01 & .15 & -.15 & -.01 & $.31^{* *}$ & $.32 * *$ & $.33^{* * *}$ & -.03 & $.67 * *$ & $.38 * *$ & (.83) & & & & & & & \\
\hline $\begin{array}{l}14 \text { Blame } \\
\text { Externalization }\end{array}$ & 1.60 & .42 & -.08 & -.02 & -.06 & .13 & .10 & .05 & $-.26 * *$ & -.15 & -.08 & $-.40^{* *}$ & $.75 * *$ & $.46^{* *}$ & $.28^{* *}$ & $(.88)$ & & & & & & \\
\hline $\begin{array}{l}15 \text { Carefree } \\
\text { Nonplanfullness }\end{array}$ & 1.83 & .31 & $.25 * *$ & .06 & -.04 & .01 & .02 & -.05 & -.05 & -.11 & .03 & -.08 & $.47 * *$ & .14 & .14 & .09 & (.69) & & & & & \\
\hline $\begin{array}{l}16 \text { Cold- } \\
\text { heartedness }\end{array}$ & 2.10 & .34 & $.20 * *$ & -.05 & .04 & .10 & $-.16^{*}$ & -.12 & $.31 * *$ & .14 & $.18^{*}$ & $.36^{* *}$ & .05 & .06 & .03 & -.13 & $.22 * *$ & $(.72)$ & & & & \\
\hline 17 Psychopathy & 2.16 & .19 & $.19 *$ & $-.21 * *$ & -.02 & $.21 * *$ & $-.21^{* *}$ & -.01 & $.74 * *$ & $.45^{* * *}$ & $.68 * *$ & $.37^{* *}$ & $.57 * *$ & $.35 * *$ & $.65^{* *}$ & $.24 * *$ & $.30^{* *}$ & $.48^{* *}$ & $(.85)$ & & & \\
\hline $\begin{array}{l}18 \text { Interpersonal } \\
\text { Influence }\end{array}$ & 5.29 & .79 & .01 & -.12 & .06 & -.01 & -.02 & $.19 *$ & $.24 * *$ & $.58^{* *}$ & -.05 & $.16^{*}$ & -.11 & .01 & .05 & $-.22 * *$ & -.10 & -.05 & .10 & (.74) & & \\
\hline $\begin{array}{l}19 \text { CWB-I } \\
\text { (Other) }\end{array}$ & 1.55 & .65 & .12 & -.14 & .02 & -.02 & -.04 & $-.18 *$ & .06 & .05 & .10 & -.04 & $.29 * *$ & $.23 * *$ & $.22^{* *}$ & $.24 * *$ & .05 & .01 & $.23^{* * *}$ & -.06 & (.89) & \\
\hline $\begin{array}{l}20 \text { Contextual } \\
\text { Perf. (Other) }\end{array}$ & 4.00 & .52 & -.07 & .02 & $.17 *$ & -.01 & -.03 & .08 & -.02 & $-.16^{*}$ & .04 & .02 & $-.16 *$ & .00 & $-.21 * *$ & -.14 & -.06 & .03 & -.11 & -.01 & $-.25 * *$ & $(.82)$ \\
\hline
\end{tabular}


Table 2

Hierarchical Moderated Regressions on Other-Rated Interpersonal-Directed Counterproductive Work Behavior (CWB-I)

\begin{tabular}{|c|c|c|c|c|c|c|c|c|c|c|c|c|}
\hline \multirow{3}{*}{$\begin{array}{l}\text { Variables } \\
\text { Predictors } \\
\end{array}$} & \multicolumn{12}{|c|}{ DV $=$ Counterproductive Work Behavior - Interpersonal (other raters) } \\
\hline & \multicolumn{2}{|c|}{ Model 1a } & \multicolumn{2}{|c|}{ Model 1b } & \multicolumn{2}{|c|}{ Model 1c } & \multicolumn{2}{|c|}{ Model 1d } & \multicolumn{2}{|c|}{ Model 1e } & \multicolumn{2}{|c|}{ Model 1f } \\
\hline & $B$ & $\beta$ & $B$ & $\beta$ & $B$ & $\beta$ & $B$ & $\beta$ & $B$ & $\beta$ & $B$ & $\beta$ \\
\hline Gender & & & & & & & .17 & .08 & & & .19 & .10 \\
\hline Age & & & & & & & -.01 & -.10 & & & -.01 & -.14 \\
\hline Educational Level & & & & & & & .04 & .06 & & & .05 & .09 \\
\hline Working Hours per Week & & & & & & & .00 & -.04 & & & -.01 & -.05 \\
\hline Years of Job Tenure & & & & & & & .01 & .10 & & & .01 & .13 \\
\hline Hierarchical Position & & & & & & & -.01 & -.17 & & & -.01 & -.15 \\
\hline Fearless Dominance (FD) & .32 & .12 & .33 & .12 & .25 & .09 & .30 & .11 & & & & \\
\hline Self-Centered Impulsivity (SCI) & $1.25 * *$ & $.30 * *$ & $1.12 * *$ & $.27 * *$ & $1.14 * *$ & $.27 * *$ & $1.07 * *$ & $.25^{* *}$ & & & & \\
\hline Cold-heartedness $(\mathrm{CH})$ & -.12 & -.04 & -.17 & -.06 & -.15 & -.05 & -.26 & -.09 & & & & \\
\hline Psychopathy (PPI-R) & & & & & & & & & $1.10 * *$ & $.21 * *$ & $1.04 *$ & $.20 *$ \\
\hline Interpersonal Influence (II) & -.08 & -.06 & .01 & .01 & .01 & .01 & .02 & .01 & -.02 & -.02 & -.01 & -.01 \\
\hline FD $x$ FD & & & -.08 & -.02 & .71 & .13 & .54 & .10 & & & & \\
\hline SCI $x$ SCI & & & 1.81 & .15 & .85 & .07 & 1.05 & .08 & & & & \\
\hline $\mathrm{CH} \times \mathrm{CH}$ & & & .01 & .00 & -.02 & .00 & .09 & .02 & & & & \\
\hline PPI-R x PPI-R & & & & & & & & & 1.14 & .05 & 1.48 & .07 \\
\hline II x II & & & .14 & $.16 \dagger$ & $.23 * *$ & $.25 * *$ & $.21 * *$ & $.24 * *$ & $.16^{*}$ & $.18^{*}$ & $.15^{*}$ & $.17^{*}$ \\
\hline FD x II & & & & & $-1.12 * *$ & $-.34 * *$ & $-1.04 * *$ & $-.31 * *$ & & & & \\
\hline PPI-R x II & & & & & & & & & $-1.39 * *$ & $-.23 * *$ & $-1.35 * *$ & $-.23 * *$ \\
\hline$R^{2}$ & .10 & & .14 & & .22 & & .26 & & .13 & & .18 & \\
\hline$F_{\left(R^{2}\right)}(d f 1, d f 2)$ & $4.14(4,1$ & $* *$ & $3.03(8$, & 2) $* *$ & $4.63(9,151)$ & & $3.35(15$, & $45)^{* *}$ & $4.64(5,1$ & $5) * *$ & 2.97 (11, & 49)** \\
\hline$\Delta R^{2}$ & & & .04 & & .08 & & .04 & & & & .05 & \\
\hline$F_{\Delta R^{2}}(d f 1, d f 2)$ & & & $1.84(4$, & & $15.12(1,15$ & $* *$ & $1.35(6,1$ & & & & $1.50(1,1$ & \\
\hline
\end{tabular}

Note. $N=161$ target-other-rater triads, control variables, moderators, and predictors were centered; dependent variable was $z$-standardized. ${ }^{\dagger} p<.10$, $* p<.05, * * p<.01$. 
Table 3

Hierarchical Moderated Regressions on Other-Rated Contextual Performance (CP)

\begin{tabular}{|c|c|c|c|c|c|c|c|c|c|c|c|c|}
\hline \multirow{3}{*}{$\begin{array}{l}\text { Variables } \\
\text { Predictors }\end{array}$} & \multicolumn{12}{|c|}{ DV = Contextual Performance (other raters) } \\
\hline & \multicolumn{2}{|l|}{ Model 2a } & \multicolumn{2}{|c|}{ Model 2b } & \multicolumn{2}{|c|}{ Model 2c } & \multicolumn{2}{|c|}{ Model 2d } & \multicolumn{2}{|c|}{ Model 2e } & \multicolumn{2}{|c|}{ Model 2f } \\
\hline & $B$ & $\beta$ & $B$ & $\beta$ & $B$ & $\beta$ & $B$ & $\beta$ & $B$ & $\beta$ & $B$ & $\beta$ \\
\hline Gender & & & & & & & -.14 & -.07 & & & -.08 & -.04 \\
\hline Age & & & & & & & .00 & -.05 & & & .00 & .00 \\
\hline Educational Level & & & & & & & $.10^{*}$ & $.17 *$ & & & .10 & .16 \\
\hline Working Hours per Week & & & & & & & -.01 & -.06 & & & -.01 & -.06 \\
\hline Years of Job Tenure & & & & & & & .00 & .00 & & & -.01 & -.06 \\
\hline Hierarchical Position & & & & & & & .01 & .13 & & & .00 & .10 \\
\hline Fearless Dominance (FD) & -.13 & -.05 & -.13 & -.05 & -.08 & -.03 & -.02 & -.01 & & & & \\
\hline Self-Centered Impulsivity (SCI) & $-.69 *$ & $-.16^{*}$ & $-.83^{*}$ & $-.20 *$ & $-.84 *$ & $-.20 *$ & $-.84 *$ & $-.20 *$ & & & & \\
\hline Cold-heartedness (CH) & .16 & .05 & .38 & .13 & .36 & .12 & .40 & .14 & & & & \\
\hline Psychopathy (PPI-R) & & & & & & & & & -.41 & -.08 & -.33 & -.06 \\
\hline Interpersonal Influence (II) & -.02 & -.02 & .04 & .03 & .04 & .03 & -.01 & -.01 & .02 & .02 & -.01 & -.01 \\
\hline FD x FD & & & .27 & .05 & -.21 & -.04 & -.25 & -.04 & & & & \\
\hline SCI x SCI & & & .72 & .06 & 1.29 & .10 & 1.49 & .12 & & & & \\
\hline $\mathrm{CH} \times \mathrm{CH}$ & & & $-1.12 * *$ & $-.24 * *$ & $-1.11 * *$ & $-.24 * *$ & $-1.10 * *$ & $-.23 * *$ & & & & \\
\hline PPI-R x PPI-R & & & & & & & & & -1.76 & -.08 & -1.58 & -.07 \\
\hline II x II & & & .06 & .06 & .00 & .01 & .02 & .02 & .04 & .05 & .05 & .06 \\
\hline FD x II & & & & & $.67 *$ & $.20 *$ & $.69 *$ & $.21 *$ & & & & \\
\hline PPI-R x II & & & & & & & & & $1.00 *$ & $.17 *$ & $.98 *$ & $.16^{*}$ \\
\hline$R^{2}$ & .03 & & .09 & & .11 & & .16 & & .05 & & .08 & \\
\hline$F_{\left(R^{2}\right)}(d f 1, d f 2)$ & $1.13(4,156)$ & & $1.79(8,152$ & & $2.16(9,1$ & 1)* & $1.84(15$, & $45)^{*}$ & $1.50(5,155)$ & & $1.24(11$ & \\
\hline$\Delta R^{2}$ & & & .06 & & .03 & & .05 & & & & .04 & \\
\hline$F_{\Delta R^{2}}(d f 1, d f 2)$ & & & $2.40(4,152$ & & $4.78(1,1$ & 1)* & $1.32(6,1$ & & & & $1.03(1$, & \\
\hline
\end{tabular}

Note. $N=161$ target-other-rater triads, control variables, moderators, and predictors were centered; dependent variable was $z$-standardized.

$* p<.05$,

$* * p<.01$. 
Figure 1

Interaction of Fearless Dominance and Interpersonal Influence on Other-Rated InterpersonalDirected Counterproductive Work Behavior (CWB-I)

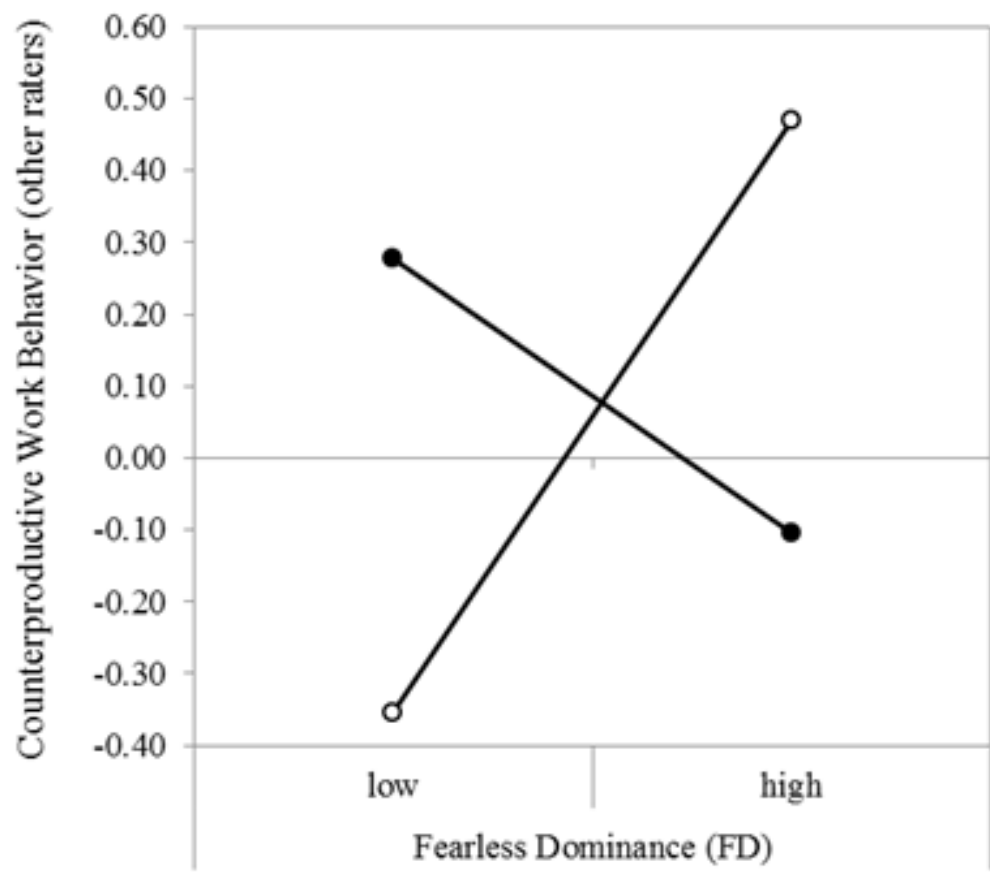

$\rightarrow$ II high

$\multimap-$ II low **

Note. $N=161$ target-other-rater triads, control variables, moderators and predictors were centered, dependent variable was $z$-standardized, II = Interpersonal Influence; low $=1 S D$ below mean; high = $1 S D$ above mean; Johnson-Neyman (Hayes, 2013) regions of significance (centered values): II $\leq-.14, \mathrm{II} \geq 1.06$; Cohen's $f^{2}$ : .06 (with control variables), .09 (without control variables);

$* * p<.01$ (slope). 
Figure 2

Interaction of Fearless Dominance and Interpersonal Influence on Contextual Performance

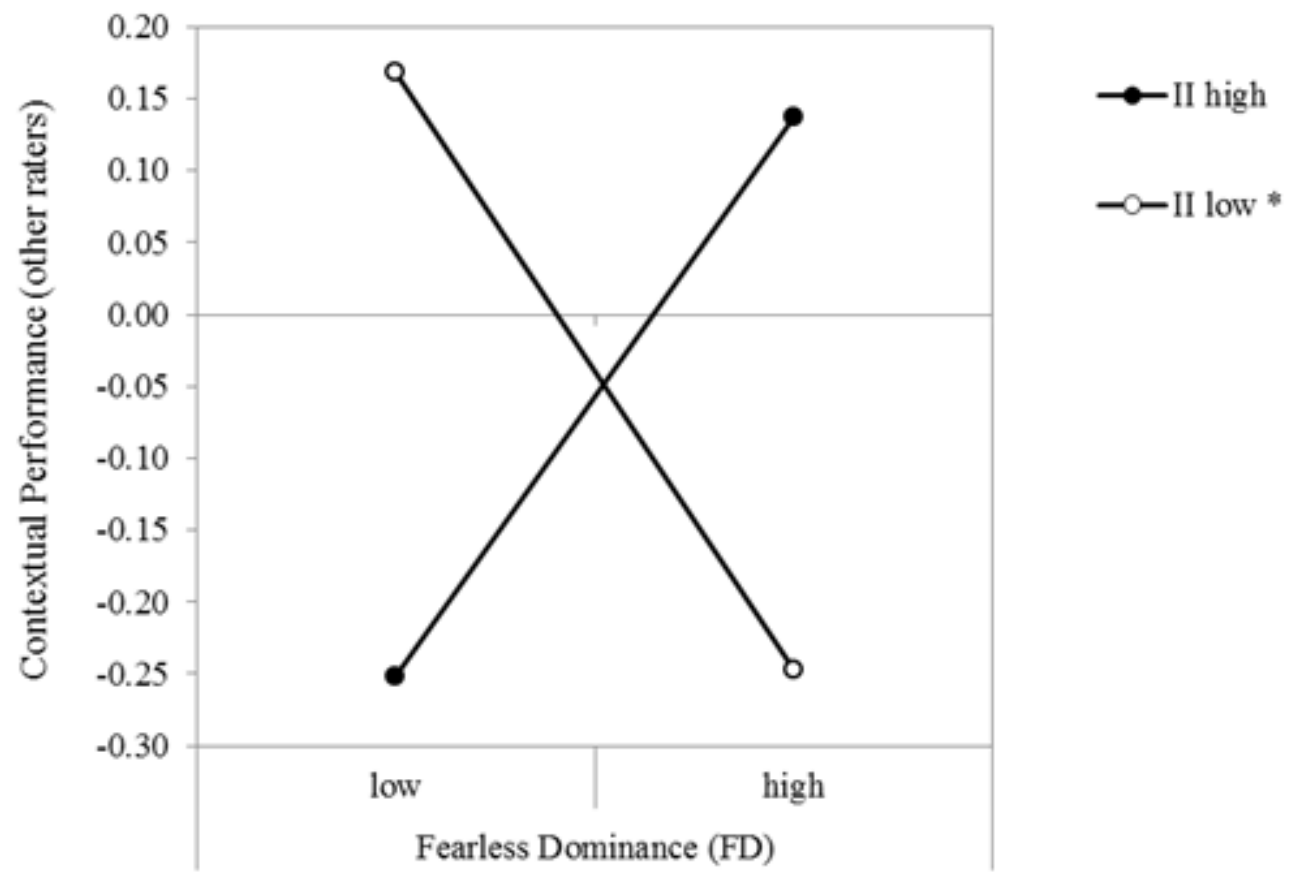

Note. $N=161$ target-other-rater triads, control variables, moderators and predictors were centered, dependent variable was $z$-standardized, II = Interpersonal Influence; low $=1 S D$ below mean; high = $1 S D$ above mean; Johnson-Neyman (Hayes, 2013) regions of significance (centered values): II $\leq-.73$, II $\geq 1.04$; Cohen's $f^{2}$ : .03 (with and without control variables);

$* p<.05$ (slope). 


\section{ONLINE APPENDIX A: SUPPLEMENTARY ANALYSES WITH THE OVERALL SCORE OF THE PPI-R}

To further examine the relationship between PPI-R and CWB-I, in supplementary analyses, we tested the interaction using the overall PPI-R score and the remaining PPI-R facets (cold-heartedness and self-centered impulsivity) and its scales. Whereas the other two facets and scales did not significantly interact with II, the overall PPI-R score was also significantly moderated by II $(\beta=-.23, p<.01)$. This interaction term also remained significant when including the control variables $(\beta=-.23, p<.01)$. Cohen's $f^{2}$ (Cohen, 1988) indicated a small to moderate effect with and without control variables $\left(f^{2}=.05\right)$.

We plotted the significant interaction of overall psychopathic personality and interpersonal influence on CWB-I following the guidelines by Cohen, Cohen, West, and Aiken (2003). As Figure A1 shows, for target employees low in II (i.e., $1 S D$ below mean), higher levels of overall PPI-R were associated with higher levels of other-rated CWB-I $(b=$ $2.11, p<.01$ ), whereas for target employees high in II (i.e., $1 S D$ above mean), overall PPI-R was not related to CWB-I $(b=-.03, n s)$. The Johnson-Neyman region of significance indicated that the relationship between PPI-R and CWB-I becomes significant below the centered value of .13 of II. Taken together, our results indicate that the interaction with interpersonal influence is specific to fearless dominance and its scales, and manifests itself at the overall psychopathy level.

We also examined the effects of the overall PPI-R score and the remaining PPI-R facets on CP. Again, whereas the other facets did not significantly interact with II, the overall PPI-R score was significantly moderated by II $(\beta=.17, p<.05)$. The interaction term, once again, remained significant when including the control variables $(\beta=.16, p<.05)$. For these effects, Cohen's $f^{2}$ (Cohen, 1988) indicated a small effect without control variables $\left(f^{2}=.03\right.$ ) and a comparable effect with control variables $\left(f^{2}=.02\right)$. The interaction of overall PPI-R 
score and II is shown in Figure A2. For target employees low in II (i.e., $1 S D$ below mean), higher levels of PPI-R were associated with lower levels of other-rated CP $(b=-1.11, p<$ $.05)$, whereas for target employees high in II (i.e., $1 S D$ above mean), PPI-R was not related to $\mathrm{CP}(b=.44, n s)$. The Johnson-Neyman region of significance indicated that the relationship between PPI-R and CP becomes significant below an II value of -.50. Additional analyses revealed that the interaction effect with the fearless dominance facet was mainly driven by the social influence scale. The interactions with fearlessness and stress immunity were not significant. Additionally, there was no significant interaction of interpersonal influence and any other psychopathy scale associated with contextual performance. 


\section{ONLINE APPENDIX B: CURVILINEAR EFFECTS OF INTERPERSONAL INFLUENCE AND COLD HEARTEDNESS}

While we did not find support for the main effect of interpersonal influence on CWB-I (H3) or CP (H4), we did detect a significant u-shaped curvilinear association between interpersonal influence and CWB-I. Following Le and colleagues (Le et al., 2011), we computed the inflection point $\left(\mathrm{II}_{\text {inflection }}=-.05\right)$, which describes a standardized score that reflects the value of II where the relation between II and CWB-I starts changing direction. The form of this curvilinear relationship can be seen in Figure B1. Accordingly, results indicated that employees with low and high levels of (self-reported) interpersonal influence were rated by others as most engaged in interpersonally counterproductive activities. More specifically, low levels of interpersonal influence were associated with heightened levels of CWB-I. This finding is consistent with the view that low skill in establishing good rapport with others and inability to adapt one's behavior to what is situationally effective would be linked to inappropriate interpersonal behavior. On the other hand, moderate levels of interpersonal influence were associated with the lowest levels of CWB-I. Finally, high levels of interpersonal influence were also associated with more CWB-I. One reason for this could be that individuals who rate themselves as in possession of high levels of interpersonal influence may be especially off-putting. For instance, in efforts to establish good rapport with some individuals, employees might make fun of, or say something disrespectful to others. Indeed, corresponding findings have been found in the school context, indicating that students low and high in perceived popularity tend to behave more aggressively towards others than those with intermediate perceived popularity (De Bruyn, Cillessen, \& Wissink, 2010; Prinstein, \& Cillessen, 2003; Walcott, Upton, Bolen, \& Brown, 2008).

Although not hypothesized, we found a significant curvilinear effect of coldheartedness on CP. As Figure B2 shows, the relationship between cold-heartedness and other- 
rated CP had an inverted $u$-shaped form, with people possessing medium to high levels of cold-heartedness $(\mathrm{CH})$ showing the most $\mathrm{CP}$. The inflection point, where the relation between $\mathrm{CH}$ and $\mathrm{CP}$ starts changing direction (Le, Oh, Robbins, Illies, Holland, \& Westrick, 2011) was $\mathrm{CH}_{\text {inflection }}=.18$.

Our results show that intermediate levels of cold-heartedness were associated with highest $\mathrm{CP}$ ratings by others, whereas (especially) low and high, respectively, levels in coldheartedness were related to less CP. Interestingly, a similar pattern has been found recently for the relation between Machiavellianism and different forms of organizational citizenship behavior (Zettler \& Solga, 2013). As cold- heartedness shares some characteristics with Machiavellianism, namely especially being callous or ruthless towards others (e.g., Furnham, Richards, \& Paulhus, 2013), and CP shows strong overlap with organizational citizenship behavior (e.g., Motowidlo \& Kell, 2012), these results might be regarded from the same perspective: In brief, Zettler and Solga (2013) assumed that in nowadays work environments - characterized by, among other things, the necessities to gain support from others, secure one's interests in negotiations, self-promote one's competencies etc., - high levels in coldheartedness do not seem very effective because it is important to be somewhat cooperative and interested in others, but it is also functional not to be too focused on others' feelings and needs. This theorizing would actually imply an inverted u-shaped pattern as found herein. Importantly, however, we want to emphasize that further investigations on the found curvilinear links seem in order before drawing more final conclusions. 


\section{REFERENCES}

Cohen, J. 1988. Statistical Power Analysis for the Behavioral Sciences (2nd ed.). Hillsdale: Lawrence Erlbaum Associates.

Cohen, J., Cohen, P., West, S., \& Aiken, L. 2003. Applied multiple regression/ correlation analysis for the behavioral sciences. Mahwah, NJ: Lawrence Erlbaum.

De Bruyn, E. H., Cillessen, A. H. N., \& Wissink, I. B. 2010. Associations of peer acceptance and perceived popularity with bullying and victimization in early adolescence., Journal of Early Adolescence, 30: 543-566.

Furnham, A., Richards, S. C. \& Paulhus, D. L. 2013. The Dark Triad of personality: A 10 Year Review. Social and Personality Psychology Compass, 7: 199-216.

Le, H., Oh, I.-S., Robbins, S. B., Ilies, R., Holland, E., \& Westrick, P. 2011. Too much of a good thing: Curvilinear relationships between personality traits and job performance. Journal of Applied Psychology, 96: 113-133.

Motowidlo, S. J., \& Kell, H. J. 2012. Job performance. In I. B. Weiner, N. W. Schmitt, \& S. Highhouse (Eds.), Handbook of Psychology, Vol. 12: Industrial and Organizational Psychology (2 $2^{\text {nd }}$ ed., pp. 82-103). New York: Wiley.

Prinstein, M. J., \& Cillessen, A. H. N. 2003. Forms and functions of adolescent peer aggression associated with high levels of peer status. Merrill-Palmer Quarterly, 49: 310-342.

Walcott, C. W., Upton, A., Bolen, L. M., \& Brown, M. B. 2008. Associations between peerperceived status and aggression in young adolescents. Psychology in the Schools, 45: $550-561$.

Zettler, I. \& Solga, M. 2013. Not enough of a "dark" trait? Linking machiavellianism to job performance. European Journal of Personality, 27: 545-554. 
Figure A1

Hierarchical moderated regressions of psychopathy on counterproductive work behavior - interpersonal rated by others (with control variables)

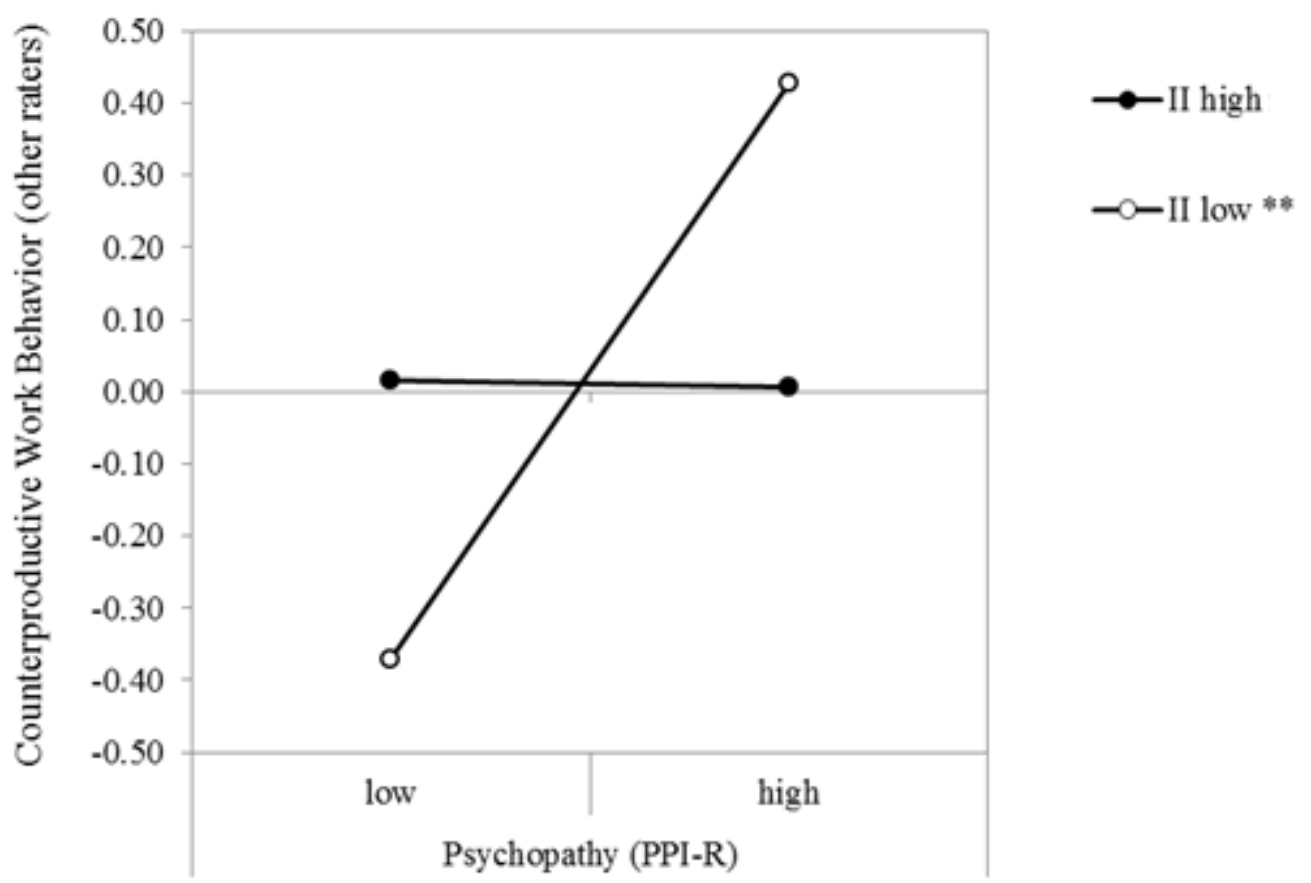

Note. $N=161$ target-other-rater triads, control variables, moderators and predictors were centered, dependent variable was $z$-standardized, II = Interpersonal Influence; low $=1 S D$ below mean; high = $1 S D$ above mean; Johnson-Neyman (Hayes, 2013) regions of significance (centered value): II $\leq .13$; Cohen's $f^{2}$ : .05 (with and without control variables); $* * p<.01$ (slope). 
Figure A2

Hierarchical moderated regressions of psychopathy on contextual performance rated by others (with control variables)

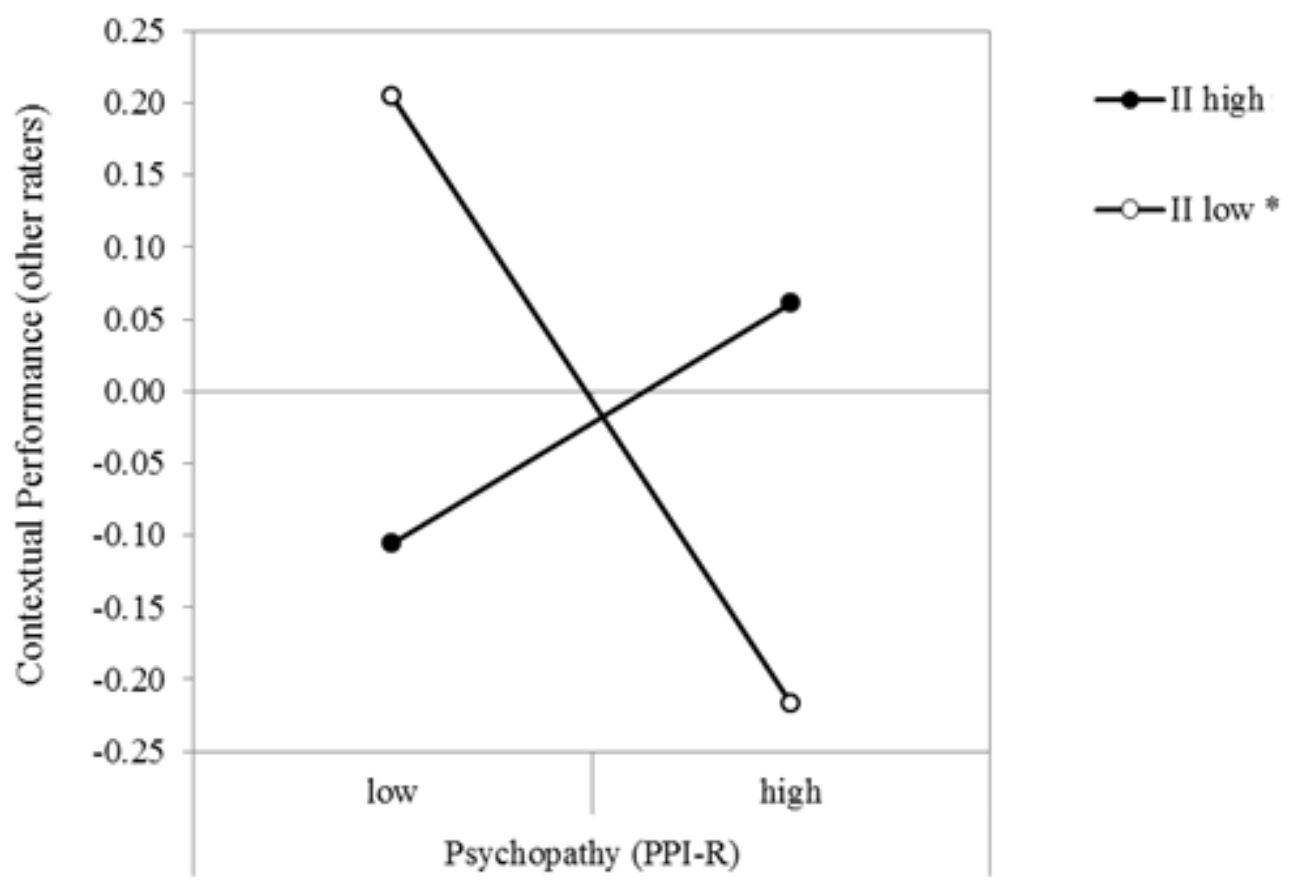

Note. $N=161$ target-other-rater triads, control variables, moderators and predictors were centered, dependent variable was $z$-standardized, II = Interpersonal Influence; low $=1 S D$ below mean; high = $1 S D$ above mean; Johnson-Neyman (Hayes, 2013) regions of significance (centered value): II $\leq-.50$; Cohen's $f^{2}$ : .02 (with control variables), .03 (without control variables);

$* p<.05$ (slope). 
Figure B1

\section{Curvilinear effect of interpersonal influence on counterproductive work behavior - interpersonal rated by others (with control variables)}

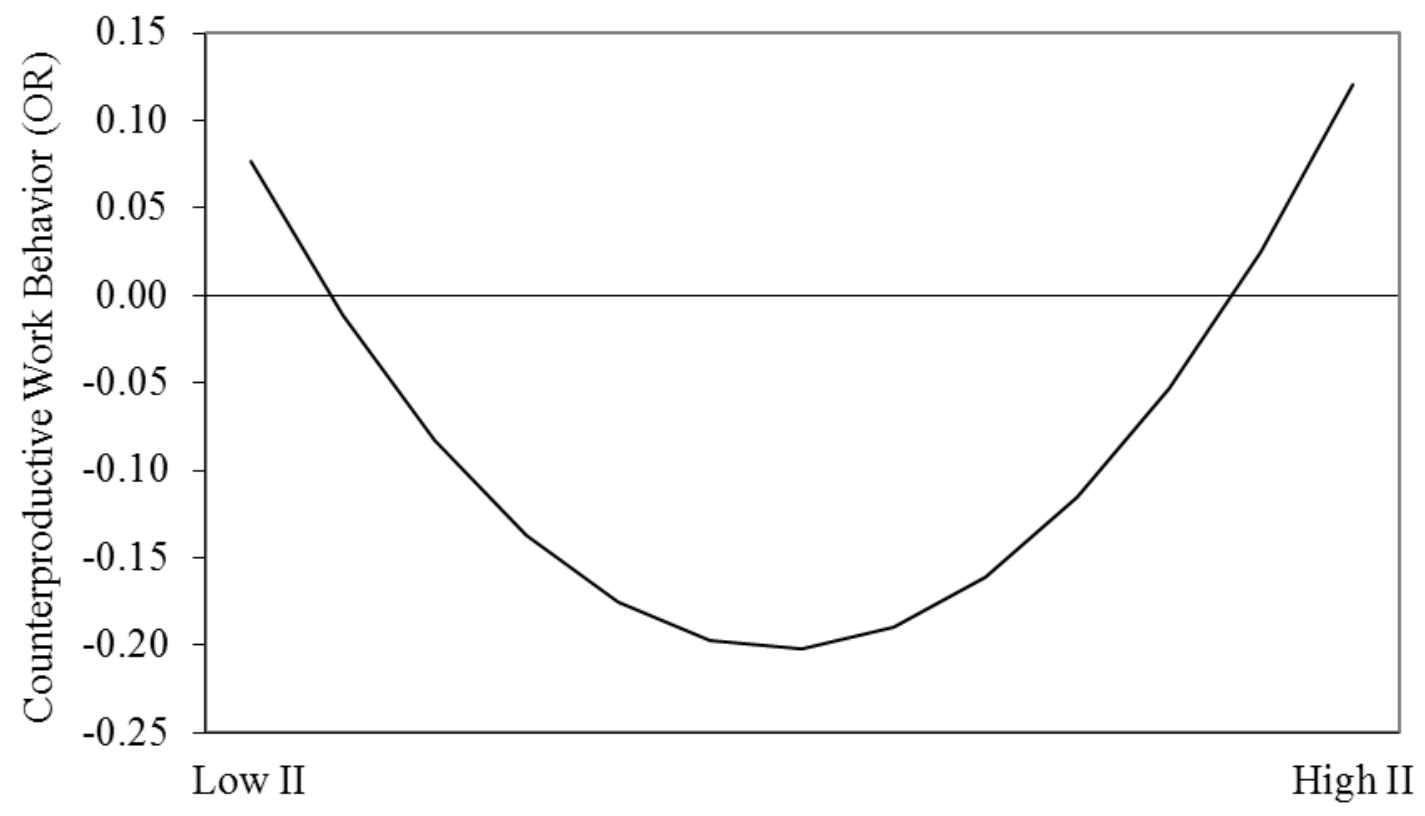

Note. $N=161$ target-other-rater triads, predictor and dependent variable were $z$-standardized, $\mathrm{II}=$ Interpersonal Influence, $\mathrm{OR}=$ other raters; low $=1 S D$ below mean; high $=1 S D$ above mean; inflection point (standardized score on the interpersonal influence scale corresponding to the inflection point of the curve reflecting the relation between interpersonal influence and counterproductive work behavior - interpersonal. That is, the relation between interpersonal influence and counterproductive work behavior - interpersonal starts changing direction at this score; Le et al., 2011, p. 121): II inflection $=-.05$. 
Figure B2

\section{Curvilinear effect of cold heartedness on contextual performance rated by others (with} control variables)

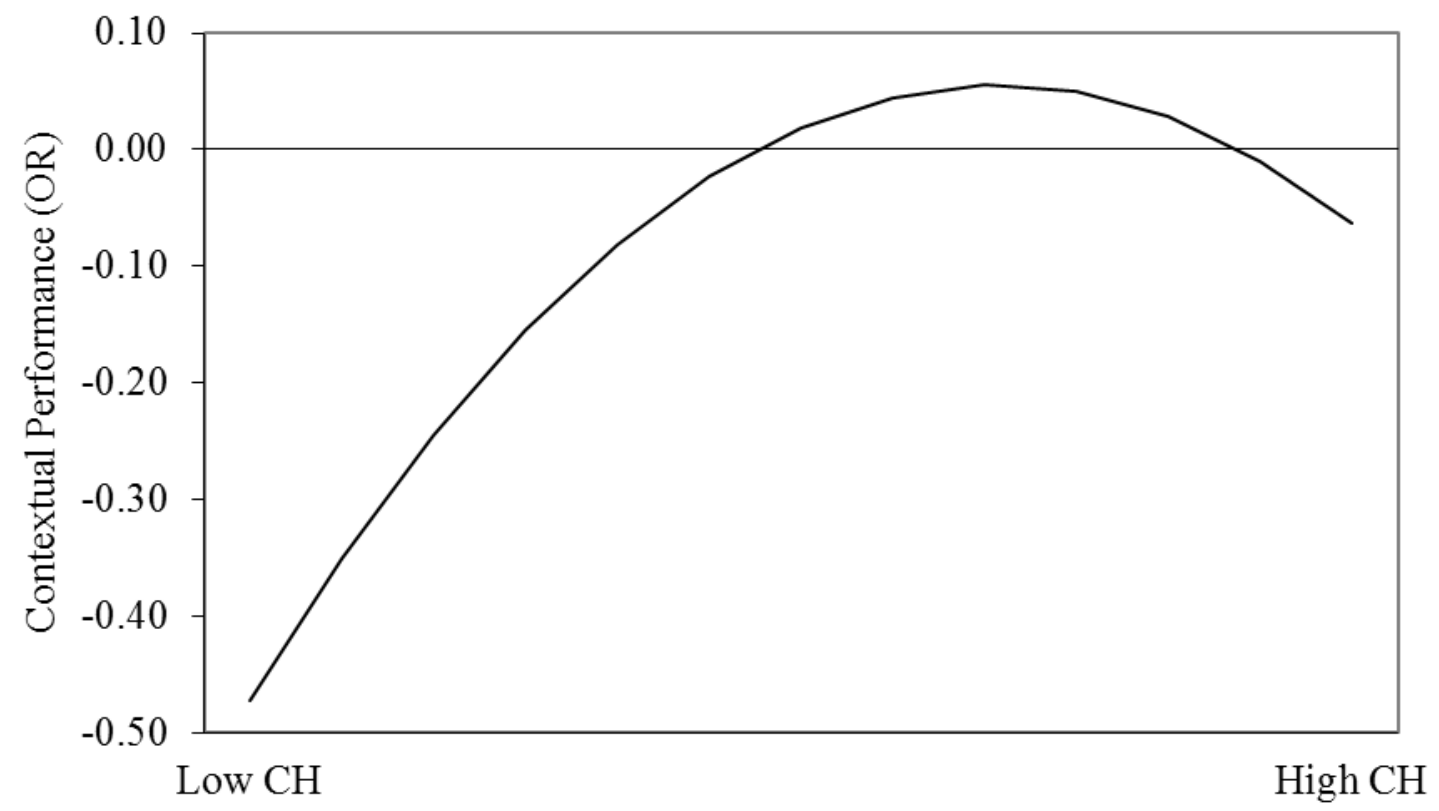

Note. $N=161$ target-other-rater triads, predictor was centered, dependent variable was $z-$ standardized, $\mathrm{CH}=$ Cold heartedness, $\mathrm{OR}=$ other raters; low $=1 S D$ below mean; high $=1$ $S D$ above mean; inflection point (standardized score on the cold heartedness scale corresponding to the inflection point of the curve reflecting the relation between cold heartedness and contextual performance. That is, the relation between cold heartedness and contextual performance starts changing direction at this score; Le et al., 2011, p. 121): $\mathrm{CH}_{\text {inflection }}=.18$. 